Original article

\title{
Towards dual antithrombotic compounds - Balancing thrombin inhibitory and fibrinogen GPIIb/IIla binding inhibitory activities of 2,3-dihydro-1,4-benzodioxine derivatives through regio- and stereoisomerism
}

\author{
Miloš Ilića ${ }^{a}$ Petra Dunkel ${ }^{\mathrm{b}}$, Janez Ilaš ${ }^{\mathrm{a}}$, Ewa Chabielska ${ }^{\mathrm{c}}$, Agnieszka Zakrzeska $^{\mathrm{c}}$, \\ Péter Mátyus $^{\mathrm{b}, * *}$, Danijel Kikelj ${ }^{\mathrm{a}, *}$ \\ ${ }^{a}$ University of Ljubljana, Faculty of Pharmacy, Aškerčeva 7, 1000 Ljubljana, Slovenia \\ ${ }^{\mathrm{b}}$ Semmelweis University, Faculty of Pharmacy, Department of Organic Chemistry, Högyes E. u. 7, 1092 Budapest, Hungary \\ ${ }^{\mathrm{c}}$ Medical University of Bialystok, Department of Biopharmacy, Mickiewicza 2c, 15-089 Bialystok, Poland
}

\section{A R T I C L E I N F O}

\section{Article history:}

Received 8 November 2012

Received in revised form

22 December 2012

Accepted 3 January 2013

Available online 10 January 2013

\section{Keywords:}

Antithrombotic

Thrombin inhibitor

GPIIb/IIIa

2,3-dihydro-1,4-benzodioxine

Dual antithrombotic compound

Multitarget

\begin{abstract}
A B S T R A C T
Enantiomers of 2,3-dihydro-1,4-benzodioxine derivatives possessing both thrombin and fibrinogen GPIIb/IIla binding inhibitory activities were prepared from $(R)$ - and $(S)$-glycidol as potential dual antithrombotic compounds. The influence of chirality and substitution pattern on thrombin inhibition and on inhibition of fibrinogen binding to GPIIb/IIIa was analyzed. Docking studies were used in an attempt to rationalize the results. The $(S)$-isomers of both 2,3-dihydro-1,4-benzodioxine regioisomers at positions 6 and 7 were found to be better thrombin inhibitors than the corresponding $(R)$-enantiomers, whereas we observed that stereochemistry does not display a consistent influence on fibrinogen GPIIb/ IIIa binding inhibitory activity. Compound 11b, the $(S)$-isomer of the 6-substituted regioisomer, possessed the best balanced dual activity, with $K_{\mathrm{i} \text { (thrombin) }}=1.67 \pm 0.27 \mu \mathrm{M}$ and IC I0(GPIIb/ IIIa) $=0.665 \pm 0.26 \mu \mathrm{M}$, raising the hope that merging anticoagulant and platelet antiaggregatory activities in the same molecule could lead to successful multitarget antithrombotic agents.
\end{abstract}

(c) 2013 Elsevier Masson SAS. All rights reserved.

\section{Introduction}

Cardiovascular diseases are the main cause of death in developed countries [1]. Existing anticoagulant and antiplatelet therapy, despite its importance and effectiveness in the treatment of cardiovascular diseases, has numerous limitations such as bleeding, metabolism that differs in different individuals due to genetic polymorphism, and interaction with other drugs and food [2,3].

During the last decade much effort have been made to design novel anticoagulant drugs that target the coagulation enzymes thrombin, factor Xa, factor VII and factor IX, with the aim of obtaining a simple and satisfactory, orally applicable replacement

Abbreviations: GPIIb/IIIa, glycoprotein IIb/IIIa; PDB, Protein Data Bank; DMAP, dimethylaminopyridine; DCM, dichloromethane; DMF, $\mathrm{N}, \mathrm{N}$-dimethylformamide; DIAD, diisopropylazodicarboxylate; TFA, trifluoroacetic acid.

* Corresponding author. Tel.: +3861 4769561; fax: +38614258031.

** Corresponding author.

E-mail address: danijel.kikelj@ffa.uni-lj.si (D. Kikelj). for the existing warfarin treatment [4-11]. Ximelagatran, a prodrug of melagatran, was the first oral direct thrombin inhibitor introduced to the market, however it was withdrawn from the market in 2006 due to expressed hepatotoxicity [12,13]. Dabigatran etexilate is a new oral prodrug for the direct thrombin inhibitor dabigatran (Fig. 1) that entered the market in 2008 for the prevention of blood clotting following hip or knee surgery, and for the prevention of stroke in patients with non-valvular atrial fibrillation [14]. Good progress has also been made in the field of direct and indirect factor Xa inhibitors. Rivaroxaban, a recently introduced, highly selective oral factor Xa inhibitor, promised effectiveness and safety in preventing venous thromboembolism [15]. Other novel factor Xa inhibitors include the recently approved apixaban, and idraparinux that is in the final stage of clinical investigation [16].

Platelets play an essential role in the maintenance of hemostasis; they are responsible for clot formation when damage of endothelium of blood vessels occurs [17]. The platelet glycoprotein IIb/IIIa antagonists abciximab, eptifibatide and tirofiban are potent antiplatelet agents, and are used to prevent pathological platelet 
<smiles>Cn1c(CNc2ccc(C(=N)N)cc2)nc2cc(C(=O)N(CCC(=O)O)c3ccccn3)ccc21</smiles>

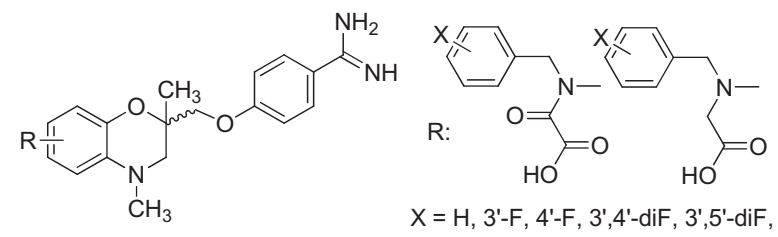

previously reported racemic 6 - and 7-substituted 1,4-benzoxazine derivatives<smiles>[R]OC(=O)C(=O)[n+]1ccc2c(c1)OCC(COc1ccc(C(=N)N)cc1)O2</smiles>

new enantiomers of 6- and 7-substituted 1,4-benzodioxines

Fig. 1. Structures of the clinically used thrombin inhibitor dabigatran, the racemic 1,4benzoxazine derivatives $[25,30]$ and the enantiomers of 1,4-benzodioxine derivatives reported in this paper.

aggregation in patients with acute coronary syndrome, heart attack and those undergoing invasive heart procedures [18].

In clinical practice, an effective prophylaxis and treatment of thromboembolic diseases, such as deep vein thrombosis, thromboembolic stroke, pulmonary embolism and myocardial infarction, is achieved by using a combination of various antiaggregatory and anticoagulant drugs [19]. Since the combined use of thrombin inhibitors and glycoprotein IIb/IIla antagonists in the prevention of cardiovascular diseases has shown additional benefits over treatment directed against thrombin or against platelets alone [20], we envisaged merging anticoagulant and platelet antiaggregatory activity in the same molecule as a promising approach towards novel multitarget antithrombotic agents [21-25]. Recently, other groups have reported the preparation of dual anticoagulant/antiplatelet agents featuring high molecular weight, polysulfated conjugates [26], in contrast to our dual acting compounds with strongly overlapping pharmacophores and low molecular weight.

In our previous work on potential dual antithrombotic compounds, combining in one molecule both thrombin inhibitory and fibrinogen receptor antagonistic activities [24,25], 3,4-dihydro- $2 \mathrm{H}$ 1,4-benzoxazine [27] was selected as a suitable scaffold, on the basis of docking experiments, enabling convenient attachment of substituents in positions 2, 4, 6 and 7 [25]. The benzamidine moiety, a typical P1 group of thrombin inhibitors and an arginine mimetic of the RGD motif [28], was attached at position 2 of the benzoxazine core, while P3 benzyl and carboxylic acid moieties, required for thrombin inhibition and GPIIb/IIIa binding [29], were bound at positions 6 or 7 of the 1,4-benzoxazine skeleton (Fig. 1). Molecular modeling studies predicted 7-isomers to be better thrombin inhibitors while 6 -isomers were expected to possess better inhibition of fibrinogen GPIIb/IIIa binding, as was later confirmed in biological assays [25]. Focusing on optimization of the P3 part, with a combination of different aromatic and carboxylate group moieties, we succeeded in preparing well-balanced dual compounds with thrombin $K_{\mathrm{i}}$ values and $\mathrm{IC}_{50}$ values for inhibition of fibrinogen binding to platelet GPIIb/IIIa in the high nanomolar/low micromolar ranges [30]. Replacement of the highly basic benzamidine moiety with the less basic [1,2,4] triazolo[4,3-b]pyridazine-6-yl group resulted in loss of both thrombin inhibitory and fibrinogen receptor antagonistic activities [31], showing the importance of the benzamidine group for binding to both targets. The failure to achieve better affinities of the designed compounds for thrombin and fibrinogen receptor demonstrates the difficulty in reaching a compromise that would meet the constraints imposed by both binding sites.

When designing multiple ligands with highly overlapping pharmacophores, balancing activities for both targets is demanding, so all structural information is of the utmost value [32-35]. In the present work we report a 1,4-benzodioxine series of enantiomeric compounds that combine, in the same molecule, highly overlapping pharmacophores of thrombin inhibitors and fibrinogen receptor antagonists (Fig. 1). They resulted from replacement of the 1,4-benzoxazine core by a 1,4-benzodioxine scaffold [36], a privileged heterocyclic skeleton applied in the design of selective $\alpha_{1}$ adrenoceptor antagonists [37], antioxidants [38,39], radical scavenging compounds [40-42], hypolipidemic [43] and antiinflammatory agents $[44,45]$. In order to explore the significance of chirality and regioisomerism in balancing the activity of the new 1,4-benzodioxine compounds at both targets, and thanks to the commercial availability of both $(R)$ - and $(S)$-glycidol (required for enantioselective synthesis of the parent 2-substituted benzodioxine cores), we prepared both enantiomers of the benzodioxine 6and 7-regioisomers and studied the effects of chirality and regioisomerism on binding the resulting potential dual antithrombotic compounds to thrombin and platelet fibrinogen receptor.

\section{Chemistry}

The synthesis of target 1,4-benzodioxine enantiomers 11ad from 4-nitrocatechol is presented in Schemes 1 and 2. The strongly electronegative nitro group in 4-nitrocatechol enabled effective control of the regioselectivity in construction of the 1,4-

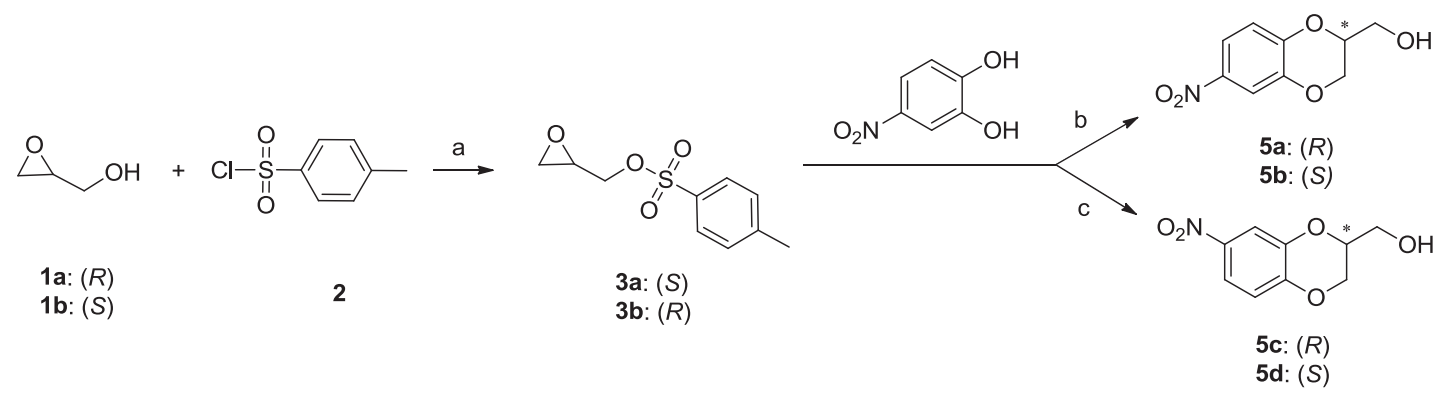

Reagents and conditions: a) Et ${ }_{3} \mathrm{~N}, \mathrm{DMAP}, \mathrm{DCM}, 0^{\circ} \mathrm{C} \rightarrow \mathrm{rt}, 1 \mathrm{~h}$; b) $\mathrm{NaH}, \mathrm{DMF}, 80^{\circ} \mathrm{C}, 2 \mathrm{~h}$; c) $\mathrm{Na}_{2} \mathrm{CO}_{3}, \mathrm{DMF}, 60^{\circ} \mathrm{C}, 2 \mathrm{~h}$. 

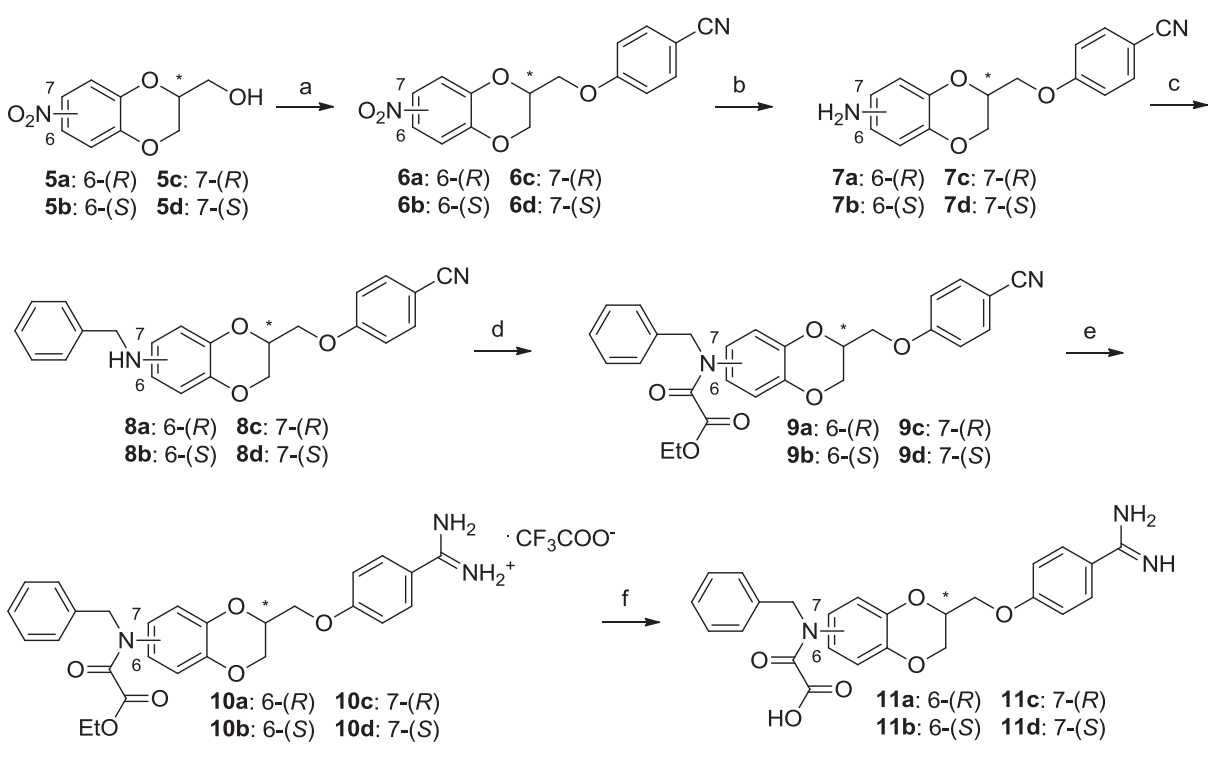

Reagents and conditions: a) 4-cyanophenol, $\mathrm{PPh}_{3}$, DIAD, THF, reflux, 48h; b) $\mathrm{H}_{2}, \mathrm{Pd} / \mathrm{C}$ (10\%), 25 bar, rt, 1h; c) benzaldehyde, $\mathrm{MeOH}$, mol. sieves, rt, 12h, then $\mathrm{NaBH}_{4}, 1 \mathrm{~h}$; d) EtOCOCOCl, $\mathrm{Et}_{3} \mathrm{~N}, \mathrm{DCM}, \mathrm{rt}, 2 \mathrm{~h} ;$ e) $\mathrm{HCl}_{(\mathrm{g})}, \mathrm{EtOH}, 0{ }^{\circ} \mathrm{C}(30 \mathrm{~min}) \rightarrow \mathrm{rt}, 24 \mathrm{~h}$, then $\mathrm{CH}_{3} \mathrm{COONH}_{4}, 24 \mathrm{~h}$; f) $1 \mathrm{M} \mathrm{LiOH}, \mathrm{THF} / \mathrm{MeOH}$, rt, $1 \mathrm{~h}$.

Scheme 2. Synthesis of compounds $10 \mathbf{a}-\mathbf{d}$ and $11 \mathbf{a}-\mathbf{d}$.

benzodioxine ring and, depending on the applied base, gave rise to 6- and 7-nitro isomers, respectively [46]. Thus, using a modified published procedure for the synthesis of the racemates [47], the reaction of 4-nitrocatechol with $(R)$ - and (S)-(2-tosyloxymethyl) oxirane (3b and $\mathbf{3 a}$ ), in the presence of potassium carbonate in $\mathrm{N}, \mathrm{N}$-dimethylformamide afforded enantiomers of (7-nitro-2,3dihydro-1,4-benzodioxin-2-yl)methanol (5d and 5c), whereas the reaction of 4-nitrocatechol with $\mathbf{3 a}$ or $\mathbf{3 b}$, using sodium hydride as a base, gave $(R)$ - and (S)-6-nitro isomers $5 \mathbf{a}$ and $\mathbf{5 b}$ (Scheme 1 ). Both nitro isomers of the $(R)$ - and $(S)$-series were reacted with 4-hydroxybenzonitrile under Mitsunobu conditions to give ethers $\mathbf{6 a}-\mathbf{d}$, which were reduced in the next step to amines $\mathbf{7 a}-\mathbf{d}$, using catalytic hydrogenation over palladium on charcoal. These were benzylated, using benzaldehyde and sodium borohydride, and the resulting $N$-benzylamines $8 \mathbf{a}-\mathbf{d}$ acylated with ethyl oxalyl chloride to give compounds $\mathbf{9 a}-\mathbf{d}$. Upon Pinner reaction they afforded esters $\mathbf{1 0 a}-\mathbf{d}$ which, after alkaline hydrolysis with lithium hydroxide in methanol/tetrahydrofuran, gave the enantiomeric carboxylic acids 11a-d (Scheme 2 ). We tried to develop an HPLC method for determining the enantiomeric purity of products 5-11, but succeeded only with compounds $\mathbf{8 a}-\mathbf{d}$ for which an enantiomeric excess $>95 \%$ was obtained. The nonracemizing conditions in the last two reaction steps and consistent optical rotation values of the products allow the conclusion that the enantiomeric excess of compounds 10a-d and 11ad remained higher than $95 \%$.

Table 1

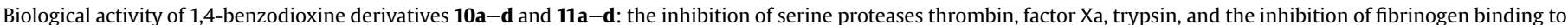
GPIIb/IIla.

\begin{tabular}{|c|c|c|c|c|c|c|c|}
\hline \multirow[t]{2}{*}{ Compound } & \multirow[t]{2}{*}{ Substitution } & \multirow[t]{2}{*}{$\mathrm{R}^{\prime}$} & \multirow[t]{2}{*}{$*$} & \multicolumn{3}{|l|}{$K_{\mathrm{i}}(\mu \mathrm{M})$} & $\mathrm{IC}_{50}(\mu \mathrm{M})$ \\
\hline & & & & Thrombin & Trypsin [selectivity] $]^{\mathrm{a}}$ & FXa [selectivity] ${ }^{\mathrm{b}}$ & GPIIb/IIIa ${ }^{c}$ \\
\hline 10a & 6 & Et & $R$ & $1.65 \pm 0.20$ & $0.644 \pm 0.089[0.39]$ & $2.15 \pm 0.18[1.30]$ & $>200$ \\
\hline 10b & 6 & Et & $S$ & $0.436 \pm 0.037$ & $0.283 \pm 0.044[0.65]$ & $1.51 \pm 0.37[3.46]$ & $>200$ \\
\hline $10 c$ & 7 & Et & $R$ & $0.675 \pm 0.099$ & $0.894 \pm 0.097[1.32]$ & $0.637 \pm 0.44[0.95]$ & $>200$ \\
\hline 10d & 7 & Et & $S$ & $0.0778 \pm 0.005$ & $0.210 \pm 0.026[2.71]$ & $2.70 \pm 0.15[35.9]$ & $>200$ \\
\hline 11a & 6 & $\mathrm{H}$ & $R$ & $5.18 \pm 1.15$ & $1.55 \pm 0.22[0.30]$ & $5.19 \pm 0.61[1.30]$ & $1.21 \pm 0.32$ \\
\hline 11b & 6 & $\mathrm{H}$ & $S$ & $1.67 \pm 0.27$ & $0.463 \pm 0.093[0.28]$ & $1.96 \pm 0.17[1.17]$ & $0.665 \pm 0.26$ \\
\hline 11c & 7 & $\mathrm{H}$ & $R$ & $2.69 \pm 0.36$ & $1.37 \pm 0.029[0.51]$ & $1.27 \pm 0.13[0.47]$ & $17.6 \pm 3.0$ \\
\hline 11d & 7 & $\mathrm{H}$ & $S$ & $0.266 \pm 0.03$ & $0.267 \pm 0.049[1.00]$ & $5.08 \pm 0.57[19.1]$ & $42.6 \pm 5.3$ \\
\hline
\end{tabular}

a Selectivity for thrombin $v s$. trypsin.

b Selectivity for thrombin vs. factor Xa.

${ }^{c}$ Compounds were also tested for inhibition of fibrinogen binding to $\alpha_{\mathrm{V}} \beta_{3}$ receptor and none of them showed binding in the test system (IC $\left.C_{50} \alpha_{\mathrm{V}} \beta_{3}\right)>200 \mu \mathrm{M}$ ). 


\section{Biological results}

Compounds 10a $-\mathbf{d}$ and 11a $-\mathbf{d}$, comprising enantiomers of the 6- and 7-isomers, were tested for inhibition of thrombin and, in order to assess their selectivity for related serine proteases, also for inhibition of factor Xa and trypsin. Additionally, they were tested for inhibition of fibrinogen binding to GPIIb/IIIa. The results are presented in Table 1 . The general structure-activity relationship which was observed in the 1,4-benzoxazine series can also be seen in the case of the 1,4-benzodioxine series. Esters $\mathbf{1 0 a}-\mathbf{d}$ were found to be more potent thrombin inhibitors than the corresponding carboxylic acids 11a-d, but they lacked fibrinogen GPIIb/IIIa binding activity $\left(\mathrm{IC}_{50}>200 \mu \mathrm{M}\right)$. Compounds bearing a P3 moiety in position 6 (11a-b) displayed more pronounced fibrinogen GPIIb/ IIla binding inhibitory activity ( $\mathrm{IC}_{50} 0.66$ and $1.21 \mu \mathrm{M}$ ), while compounds bearing a P3 moiety at position 7 exhibited more pronounced thrombin inhibitory activity $\left(K_{\mathrm{i}}=0.078-2.69 \mu \mathrm{M}\right)$. While compounds 10a- $-\mathbf{d}$ and $11 \mathbf{a}-\mathbf{d}$ were not selective towards two similar serine proteases, trypsin and factor $\mathrm{Xa}$, the compound with the most potent thrombin inhibitory activity (10d) was found also to be the most selective. As demonstrated in Fig. 1, compound 11b, the $(S)$-isomer of the 6-substituted regioisomer, possessed the best balanced dual activity $\left(K_{\mathrm{i}(\mathrm{thr})}=1.67 \pm 0.27 \mu \mathrm{M}, \mathrm{IC}_{50}\right.$ (GPIIb/ IIIa) $=0.665 \pm 0.26 \mu \mathrm{M})$. Compound 10d, the $(S)$-isomer of the 7-regioisomer, is the most potent thrombin inhibitor, with $K_{\mathrm{i}(\mathrm{thr})}=77.8 \pm 5.0 \mathrm{nM}$, and compound 11b, ((S)-isomer of the 6regioisomer) has the most potent fibrinogen GPIIb/IIIa binding inhibitory activity, with $\mathrm{IC}_{50 \text { (IIb/IIIa) }}=665 \pm 260 \mathrm{nM}$. This demonstrates that, in the development of dual antithrombotic compounds based on the 1,4-benzodioxine scaffold, optimizing fibrinogen receptor activity is a more difficult task than optimizing thrombin inhibition.

The $(S)$-isomers of the 6- and 7-series were found to be better thrombin inhibitors than the $(R)$-isomers. Overall, these results are comparable with those for the 1,4-benzoxazine analogues. The racemic 1,4-benzoxazine derivative substituted at position 6 showed higher activity on both targets $\left(K_{\mathrm{i}(\mathrm{thr})}=0.62 \pm 0.10 \mu \mathrm{M}\right.$, $\left.\mathrm{IC}_{50(\mathrm{GPII} / \mathrm{III})}=2.8 \pm 1.5 \mu \mathrm{M}\right)$, while the racemic 1,4-benzoxazine derivative substituted at position 7 had more pronounced thrombin inhibitory activity $\left(K_{\mathrm{i}(\mathrm{thr})}=0.19 \pm 0.02 \mu \mathrm{M}\right.$, IC 50 (GPIIb/ IIIa) $=39 \pm 18 \mu \mathrm{M}$ ) [26]. When considering eudismic ratios, the results in Table 1 demonstrate that, in the case of esters $10 \mathbf{a}-\mathbf{d}$ in the 6 -regioisomer series, the $(S)$-isomer is 3.8 times more potent and, in the 7-regioisomer series, 8.7 times more potent thrombin inhibitor than corresponding $(R)$-isomer. Similar results are seen in the case of acids 10a-d where, in 6-substituted compounds, the $(S)$-isomer is 3.1 times more potent and, in the 7-substituted compound, 10.1-fold more potent as a thrombin inhibitor. Stereochemistry does not appear to have such a consistent influence on fibrinogen GPIIb/IIIa binding inhibitory activity. In the case of the 6substituted compound, the $(S)$-isomer $\mathbf{1 1 b}$ is 1.8 times more potent than the $(R)$-isomer 11a, while in case of 7-substituted compounds the $(R)$-isomer 11c is 2.4 times more potent than the $(S)$-isomer 11d. It can thus be concluded that, in the 1,4-benzodioxine series, the (S)-6-isomers offer the best opportunities for optimization towards balanced dual acting compounds.

\section{Docking studies}

In an attempt to rationalize the differences in the binding affinities of $(R)$ - and $(S)$-enantiomers for thrombin and fibrinogen receptor, we performed docking of compounds 11a and 11b - both enantiomers of the more balanced 6-regioisomer docked to the thrombin active site and to the binding site of GPIIb/IIIa are depicted in Fig. 2. Given the similarity of our compounds to dabigatran, the crystal structure of the dabigatran-thrombin complex (PDB: 1KTS) [48] was used for docking experiments. Compounds 11a and 11b bind to the thrombin active site in a similar manner to dabigatran but the configuration at chiral centers slightly influences the difference in their binding modes. The distance between the C-atoms of the Asp189 carboxylate and the amidine group is $3.9 \AA$ and $4.0 \AA$ for $\mathbf{1 1} \mathbf{a}$ and $\mathbf{1 1 b}$, and two hydrogen bonds connect the amidine hydrogens and carboxylate oxygen atoms. Additional hydrogen bonds of $1.98 \AA$ and 2.0 Å between the benzamidine and the Gly219 backbone for the two compounds are observed. The 2,3-dihydro-1,4-benzodioxine scaffold is located in the $\mathrm{S} 2$ binding pocket and the benzyl group reaches into the lipophilic S3 binding pocket, with the P3 carboxylate stretching
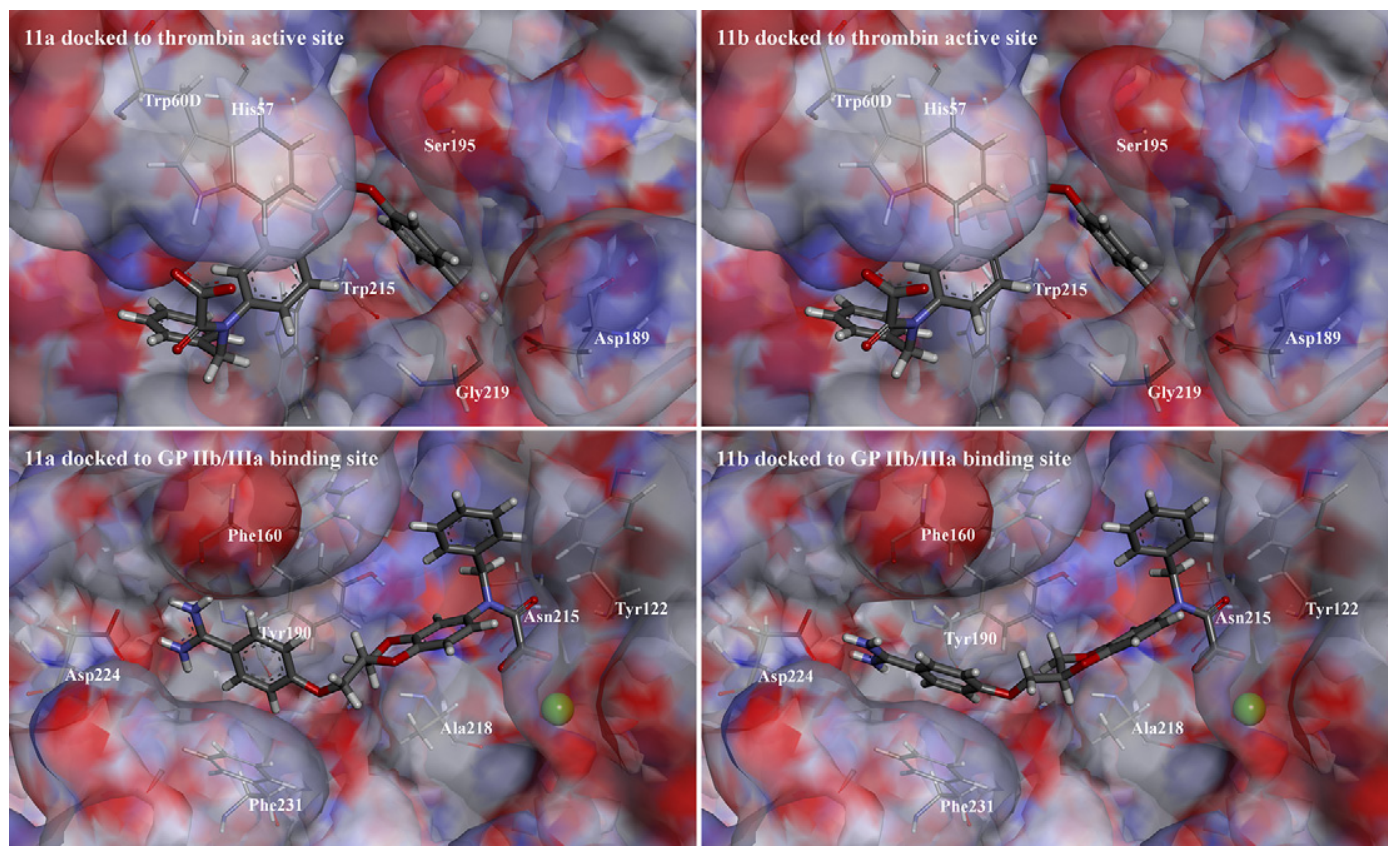

Fig. 2. Compounds 11a ( $R$-isomer, left) and 11b (S-isomer, right) docked to thrombin active site (top) and GPIIb/IIIa binding site (bottom). 
outwards from the thrombin surface. The methyleneoxy groups adjacent to the chiral carbon of 3,4-dihydro-1,4-benzodioxine are oriented differently in the two enantiomers. The distance between the oxygen of the methyleneoxy group and the Ser195 OH group $(\mathrm{O}-\mathrm{H} \bullet \bullet \bullet \mathrm{O})$ is $3.1 \AA$ in $\mathbf{1 1} \mathbf{b}$ and $3.6 \AA$ in 11a. The carbon atom of the methylenoxy groups adjacent to the chiral center is the atom that differs most in its positioning in 11a and 11b-by $1.92 \AA$. In $\mathbf{1 1 b}$, the methylene group is closer to the protein surface while, in 11a, it points outwards from the thrombin surface.

The analysis of the binding modes of 11a and 11b docked in the binding site of GPIIb/IIIa (using PDB: 2VDM - the only published crystal structure of GPIIb/IIIa in a complex with a low molecular weight RGD mimetic) [49] shows that the compounds take an extended conformation. The carboxylic acid moiety occupies an identical location in 11a and 11b, making electrostatic interactions with the $\mathrm{Mg}^{2+}$ atom and hydrogen-bonding to the amide proton of Asn215 of the $\beta_{3}$ subunit of the GPIIb/IIIa. The phenyl rings of 11a and 11b also occupy identical positions, making hydrophobic interactions with Tyr122 of the $\beta_{3}$ subunit. The methylenoxy groups and the benzamidine moieties of 11a and 11b occupy slightly different positions. The Ala218 of the $\beta_{3}$ subunit makes, with its methyl group, hydrophobic interactions with the exocyclic methylenoxy group of the ligand (distances of $4.2 \AA$ for $\mathbf{1 1 b}$ and $5.5 \AA$ for 11a) and polar interactions of its $C=0$ group with the exocyclic ether oxygen of the ligand ( $2.9 \AA$ A for $\mathbf{1 1} \mathbf{b}$ and 3.3 Å for 11a). Further, positioning of the benzamidine moiety, which forms hydrogen bonds with Asp224 and the Phe160 from the $\alpha_{\mathrm{IIb}}$ subunit of the GPIIb/IIIa, and hydrophobic interactions with Tyr190, Phe231, and Phe191 of the $\alpha_{\text {IIb }}$ subunit, differs between the $R$ - and $S$-isomers by $0.94 \AA$ difference in the position of the carbon atom of the amidine moieties of 11a and 11b. The docking experiments thus show better binding interactions of $\mathbf{1 1 b}$ than that of 11a to platelet fibrinogen receptor (GPIIb/IIIa).

In summary, the measured activities and analysis of the docking positions of 11a and 11b at the two targets lead to the conclusion that the configuration at the chiral center, and the consequent different positioning of the methylenoxy moiety, accounts, at least partly, for the difference in potency of the two enantiomers. Whereas the methylenoxy moiety situated in close proximity to the chiral center is required for flexibility of the molecule (compounds 10a-11d adopt a bent shape in the thrombin active site and extended conformations in the fibrinogen receptor-binding site), this could also explain the low eudismic ratios resulting from the $\mathrm{CH}_{2} \mathrm{O}$ - group imposed molecular flexibility that diminishes the difference between the binding conformations of two enantiomers at a particular target.

\section{Conclusion}

A novel 1,4-benzodioxine enantiomeric series of compounds have been prepared that act both as thrombin inhibitors and as fibrinogen GPIIb/IIIa binding inhibitors. The influence of chirality and regioisomerism on their thrombin inhibitory and fibrinogen GPIIb/IIIa binding inhibitory activities has been analyzed. The differences in potency of isomers and observed eudismic ratios can be explained in terms of the docking poses of the two stereoisomers. Unfortunately, we were not able to observe antithrombotic action of this series of compounds in in vivo model of venous thrombosis in rat, indicating that their potencies on both targets are still too weak to be measured in vivo. The attempt to balance thrombin inhibition and fibrinogen GPIIb/IIIa binding inhibitory activities on the one hand and to achieve lower nanomolar $K_{\mathrm{i}}$ (thrombin) and $\mathrm{IC}_{50}$ (GPIIb/IIIa) values on the other - which could result in in vivo antithrombotic activity - remains a viable, but highly demanding challenge in the search for effective dual antithrombotic drugs.

\section{Experimental section}

\subsection{General}

Chemicals were obtained from Acros, Aldrich Chemical Co. and Fluka and used without further purification. Analytical TLC was performed on silica gel Merck $60 \mathrm{~F}_{254}$ plates $(0.25 \mathrm{~mm})$, using visualization with ultraviolet light. Column chromatography was carried out on silica gel 60 (particle size 240-400 mesh). Melting points were determined on a Reichert hot stage microscope and are uncorrected. ${ }^{1} \mathrm{H}$ NMR and ${ }^{13} \mathrm{C}$ NMR spectra were recorded on a $400 \mathrm{MHz}$ Bruker AVANCE III NMR spectrometer $\left({ }^{1} \mathrm{H}\right.$ NMR at $400.13 \mathrm{MHz}$ and ${ }^{13} \mathrm{C}$ NMR at $100.61 \mathrm{MHz}$ ) and on a Bruker Avance DPX300 spectrometer $\left({ }^{1} \mathrm{H}\right.$ NMR at $300 \mathrm{MHz},{ }^{13} \mathrm{C}$ NMR at $\left.75 \mathrm{MHz}\right)$ in DMSO- $\mathrm{d}_{6}$ solution, with TMS as internal standard. ${ }^{13} \mathrm{C}$ NMR spectra were assigned using gradient COSY, HSQC and HMBC experiments. The following abbreviations were used to describe peak splitting patterns wherever appropriate: $\mathrm{br}=$ broad, $\mathrm{d}=$ doublet, $\mathrm{dd}=$ doublet of doublet, $\mathrm{t}=$ triplet, $\mathrm{q}=$ quartet, and $\mathrm{m}=$ multiplet. IR spectra were recorded on a Perkin-Elmer 1600 FT-IR spectrometer. Microanalyses were performed on a Perkin-Elmer C, H, N Analyzer 240 C. Analyses indicated by the symbols of the elements were within $\pm 0.4 \%$ of the theoretical values. Mass spectra were obtained using a VG-Analytical Autospec Q mass spectrometer. Optical rotations were measured on a Perkin-Elmer 1241 MC polarimeter. Reverse phase HPLC was performed on an Agilent Technologies HP 1100 instrument with G1365B UV-vis detector (254 nm), using an Eclipse Plus C18 column $5 \mu \mathrm{m}(4.6 \times 150 \mathrm{~mm})$ at flow rate of $1 \mathrm{~mL} / \mathrm{min}$. The eluent was a mixture of $0.1 \%$ TFA in water (A) and methanol (B) and the gradient was $40 \%$ B to $80 \%$ B in $15 \mathrm{~min}$. Chiral HPLC analyses were performed on a JASCO ChromPass Software Version 1.8 with JASCO UV-2075 UV-vis detector $(244 \mathrm{~nm})$, using a Chiralcel OJ-H $5 \mu \mathrm{m} 4.6 \times 250 \mathrm{~mm}$ column at flow rate of $1 \mathrm{~mL} / \mathrm{min}$. Compounds were separated under isocratic conditions using as eluent a mixture of $60 \% n$-hexane and $40 \%$ ethanol. All the compounds reported in this paper were $>95 \%$ pure. Esters 10a-d were purified by reverse phase column chromatography, using a Flash Purification System ISOLERA ${ }^{\mathrm{TM}}$. The eluent was a mixture of $0.1 \%$ TFA in water (A) and methanol (B) and the gradient was $40 \%$ B to $80 \%$ B in 30 column volumes.

\subsection{Synthesis of (R)-glycidyl tosylate (3b)}

To a solution of (S)-glycidol (5.50 g, $74.24 \mathrm{mmol})$, triethylamine $(8.26 \mathrm{~g}, 81.66 \mathrm{mmol})$ and 4 -(dimethylamino)pyridine $(2 \%, 181 \mathrm{mg}$, $1.48 \mathrm{mmol}$ ) in $60 \mathrm{~mL}$ dichloromethane at $0{ }^{\circ} \mathrm{C}$, tosyl chloride (14.15 g, $74.24 \mathrm{mmol}$ ) was added and the mixture was stirred at room temperature for $3 \mathrm{~h}$ with formation of a white precipitate. Dichloromethane $(40 \mathrm{~mL})$ was added and the mixture was subsequently washed with $100 \mathrm{~mL} 5 \%$ aq. $\mathrm{K}_{2} \mathrm{CO}_{3}, 100 \mathrm{~mL} 1 \mathrm{M} \mathrm{HCl}$, and $100 \mathrm{~mL}$ water. The organic layer was dried over $\mathrm{Na}_{2} \mathrm{SO}_{4}$, filtered and evaporated to dryness. The crude product (15.56 g colourless oil, $92 \%$ yield) was used in the next step without further purification; $[\alpha]_{\mathrm{D}}=-16.7\left(c=0.46, \mathrm{CHCl}_{3}\right)$, lit.: $[50][\alpha]_{\mathrm{D}}=-17.0(c=2.83$, $\left.\mathrm{CHCl}_{3}\right) ;{ }^{1} \mathrm{H}$ NMR $\left(300 \mathrm{MHz}, \mathrm{CDCl}_{3}\right): \delta(\mathrm{ppm}) 2.47\left(\mathrm{~s}, 3 \mathrm{H}, \mathrm{CH}_{3}\right), 2.61$ $\left(\mathrm{dd}, J=4.8,2.5 \mathrm{~Hz}, 1 \mathrm{H}, \mathrm{CH}_{2} \mathrm{O}\right), 2.83\left(\mathrm{t}, J=.4 \mathrm{~Hz}, 1 \mathrm{H}, \mathrm{CH}_{2} \mathrm{O}\right), 3.16-3.24$ ( $\mathrm{m}, 1 \mathrm{H}, \mathrm{CH}$ ), 4.0 (dd, $J=11.4,6.0 \mathrm{~Hz}, 1 \mathrm{H}, \mathrm{CH}_{2} \mathrm{OS}$ ), 4.27 (dd, $J=11.4$, $\left.3.5 \mathrm{~Hz}, 1 \mathrm{H}, \mathrm{CH}_{2} \mathrm{OS}\right), 7.37\left(\mathrm{~d}, J=8.1 \mathrm{~Hz}, 2 \mathrm{H}, \mathrm{Ar}-\mathrm{H}^{3}, \mathrm{Ar}-\mathrm{H}^{5}\right), 7.82(\mathrm{~d}$, $\left.J=8.1 \mathrm{~Hz}, 2 \mathrm{H}, \mathrm{Ar}-\mathrm{H}^{2}, \mathrm{Ar}-\mathrm{H}^{6}\right)$.

\subsection{Synthesis of (S)-glycidyl tosylate (3a)}

To a solution of $(R)$-glycidol (4.00 g, $54.00 \mathrm{mmol})$, triethylamine $(6.01 \mathrm{~g}, 59.50 \mathrm{mmol})$ and 4 -(dimethylamino)pyridine $(2 \%, 132 \mathrm{mg}$, $1.08 \mathrm{mmol}$ ) in $50 \mathrm{~mL}$ dichloromethane at $0^{\circ} \mathrm{C}$, tosyl chloride $(10.30 \mathrm{~g}$, 
$54.00 \mathrm{mmol}$ ) was added and the mixture was stirred at room temperature for $1 \mathrm{~h}$. During stirring a white precipitate was formed. The reaction mixture was subsequently washed with $100 \mathrm{~mL} 5 \%$ aq. $\mathrm{K}_{2} \mathrm{CO}_{3}, 100 \mathrm{~mL} 1 \mathrm{M} \mathrm{HCl}$, and $100 \mathrm{~mL}$ water. The organic layer was dried over $\mathrm{Na}_{2} \mathrm{SO}_{4}$, filtered and evaporated to dryness. The crude product (11.63 g colourless oil, 95\% yield) was used in the next step without further purification; $[\alpha]_{\mathrm{D}}=+16.3\left(c=0.57, \mathrm{CHCl}_{3}\right)$, lit.: [51] $[\alpha]_{\mathrm{D}}=+17.5\left(c=2.13, \mathrm{CHCl}_{3}\right) ;{ }^{1} \mathrm{H}$ NMR $\left(300 \mathrm{MHz}, \mathrm{CDCl}_{3}\right): \delta(\mathrm{ppm})$ $2.47\left(\mathrm{~s}, 3 \mathrm{H}, \mathrm{CH}_{3}\right), 2.61\left(\mathrm{dd}, J=4.8,2.5 \mathrm{~Hz}, 1 \mathrm{H}, \mathrm{CH}_{2} \mathrm{O}\right), 2.81-2.85(\mathrm{~m}, 1 \mathrm{H}$, $\mathrm{CH}_{2} \mathrm{O}$ ), 3.17-3.24 (m, $\left.1 \mathrm{H}, \mathrm{CH}\right), 3.98$ (dd, $J=11.4,6.0 \mathrm{~Hz}, 1 \mathrm{H}, \mathrm{CH}_{2} \mathrm{OS}$ ), 4.27 (dd, $J=11.4,3.5 \mathrm{~Hz}, 1 \mathrm{H}, \mathrm{CH}_{2} \mathrm{OS}$ ), 7.37 (d, $J=8.1 \mathrm{~Hz}, 2 \mathrm{H}, \mathrm{Ar}-\mathrm{H}^{3}$, $\left.\mathrm{Ar}-\mathrm{H}^{5}\right), 7.83\left(\mathrm{~d}, J=8.1 \mathrm{~Hz}, 2 \mathrm{H}, \mathrm{Ar}-\mathrm{H}^{2}, \mathrm{Ar}-\mathrm{H}^{6}\right)$.

\subsection{Synthesis of (R)-(6-nitro-2,3-dihydro-1,4-benzodioxin-2-yl) methanol (5a)}

To a suspension of $\mathrm{NaH}$ (60\% dispersion, $120 \mathrm{mg}, 1.5 \mathrm{mmol}$ ) in $5 \mathrm{~mL}$ DMF at $0{ }^{\circ} \mathrm{C}$, 4-nitrocatechol (310 $\mathrm{mg}, 2.00 \mathrm{mmol}$ ) in $1 \mathrm{~mL} \mathrm{DMF}$ was added carefully. The mixture was stirred at $0{ }^{\circ} \mathrm{C}$ for $30 \mathrm{~min}$ (until gas formation ceased) and then a solution of (S)-glycidyl tosylate ( $502 \mathrm{mg}, 2.20 \mathrm{mmol}$ ) in $1 \mathrm{~mL}$ DMF was added. The reaction mixture was stirred at room temperature for $30 \mathrm{~min}$ and then heated at $80^{\circ} \mathrm{C}$ for $2 \mathrm{~h}$. Upon cooling, the mixture was poured onto $15 \mathrm{~mL}$ water. The mixture was extracted with $3 \times 20 \mathrm{~mL}$ diethyl ether. The combined organic phases were dried over $\mathrm{Na}_{2} \mathrm{SO}_{4}$, filtered and evaporated to dryness. The crude product obtained was purified by column cromatography (petrolether:ethyl acetate $1: 1$ ) to give $178 \mathrm{mg}(42 \%)$ of pale yellow crystals; mp $112-114{ }^{\circ} \mathrm{C}$; $[\alpha]_{\mathrm{D}}=+87.61\left(c=0.57, \mathrm{CHCl}_{3}\right) ;{ }^{1} \mathrm{H}$ NMR $\left(300 \mathrm{MHz}, \mathrm{CDCl}_{3}\right)$ : $\delta(\mathrm{ppm}) 1.91(\mathrm{t}, J=6.20 \mathrm{~Hz}, 1 \mathrm{H}, \mathrm{OH}), 3.86-4.04\left(\mathrm{~m}, 2 \mathrm{H}, \mathrm{CH}_{2} \mathrm{OH}\right)$, 4.09-4.28 (m, $1 \mathrm{H}, \mathrm{CH}), 4.33-4.47\left(\mathrm{~m}, 2 \mathrm{H}, \mathrm{CH}_{2} \mathrm{O}\right), 6.94-7.08(\mathrm{~m}, 1 \mathrm{H}$, $\left.\mathrm{Ar}-\mathrm{H}^{8}\right), 7.75-7.90\left(\mathrm{~m}, 2 \mathrm{H}, \mathrm{Ar}-\mathrm{H}^{5}, \mathrm{Ar}-\mathrm{H}^{7}\right)$.

\subsection{Synthesis of (S)-(6-nitro-2,3-dihydro-1,4-benzodioxin-2-yl) methanol (5b)}

To a suspension of $\mathrm{NaH}$ (60\% dispersion, $120 \mathrm{mg}, 1.5 \mathrm{mmol}$ ) in $5 \mathrm{~mL}$ DMF at $0{ }^{\circ} \mathrm{C}$, 4-nitrocatechol (310 mg, $2.00 \mathrm{mmol}$ ) in $1 \mathrm{~mL}$ DMF was added. The mixture was stirred at $0^{\circ} \mathrm{C}$ for $30 \mathrm{~min}$ (until gas formation ceased) and then a solution of $(R)$-glycidyl tosylate $(502 \mathrm{mg}$, $2.20 \mathrm{mmol}$ ) in $1 \mathrm{mLDMF}$ was added. The reaction mixture was stirred at room temperature for $30 \mathrm{~min}$ and then heated at $80^{\circ} \mathrm{C}$ for $2 \mathrm{~h}$. Upon cooling, the mixture was poured onto $15 \mathrm{~mL}$ water. The mixture was extracted with $3 \times 20 \mathrm{~mL}$ diethyl ether. The combined organic phases were dried over $\mathrm{Na}_{2} \mathrm{SO}_{4}$, filtered and evaporated to dryness. The crude product obtained was purified by column cromatography (petrolether:ethyl acetate $=1: 1$ ) to give $212 \mathrm{mg}$ (50\%) of pale yellow crystals; mp $112-114{ }^{\circ} \mathrm{C} ;[\alpha]_{\mathrm{D}}=-86.6\left(\mathrm{c}=0.51, \mathrm{CHCl}_{3}\right) ;{ }^{1} \mathrm{H}$ NMR $\left(300 \mathrm{MHz}, \mathrm{CDCl}_{3}\right): \delta(\mathrm{ppm}) 1.91(\mathrm{t}, J=6.20 \mathrm{~Hz}, 1 \mathrm{H}, \mathrm{OH}), 3.85-4.04(\mathrm{~m}$, $\left.2 \mathrm{H}, \mathrm{CH}_{2} \mathrm{OH}\right), 4.10-4.25(\mathrm{~m}, 1 \mathrm{H}, \mathrm{CH}), 4.33-4.46\left(\mathrm{~m}, 2 \mathrm{H}, \mathrm{CH}_{2} \mathrm{O}\right), 6.95-$ $7.04\left(\mathrm{~m}, 1 \mathrm{H}, \mathrm{Ar}-\mathrm{H}^{8}\right), 7.76-7.88\left(\mathrm{~m}, 2 \mathrm{H}, \mathrm{Ar}-\mathrm{H}^{5}, \mathrm{Ar}-\mathrm{H}^{7}\right)$.

6.6. Synthesis of (R)-(7-nitro-2,3-dihydro-1,4-benzodioxin-2-yl) methanol (5c)

A suspension of 4-nitrocatechol (310 $\mathrm{mg}, 2.00 \mathrm{mmol}),(S)$-glycidyl tosylate ( $545 \mathrm{mg}, 2.40 \mathrm{mmol}$ ) and $\mathrm{K}_{2} \mathrm{CO}_{3}$ (663 mg, $4.80 \mathrm{mmol}$ ) in $5 \mathrm{~mL}$ DMF was heated at $60^{\circ} \mathrm{C}$ for $2 \mathrm{~h}$. The mixture was poured onto $15 \mathrm{~mL}$ water and extracted with $3 \times 20 \mathrm{~mL}$ diethyl ether. The combined organic phases were subsequently washed with $3 \times 20 \mathrm{~mL} 10 \%$ aq. $\mathrm{K}_{2} \mathrm{CO}_{3}, 20 \mathrm{~mL}$ water and $20 \mathrm{~mL}$ brine. The organic layer was dried over $\mathrm{Na}_{2} \mathrm{SO}_{4}$, filtered and evaporated to dryness. The crude product obtained was purified by column cromatography (petrolether:ethyl acetate $=1: 1$ ) to give $191 \mathrm{mg}$ of pale yellow crystals $(45 \%) ; \mathrm{mp} 117-119{ }^{\circ} \mathrm{C} ;[\alpha]_{\mathrm{D}}=+59.72\left(c=0.5\right.$ in $\left.\mathrm{CHCl}_{3}\right)$, lit.: $[52]+65.5(c=0.58,96 \%$ EtOH $) ;{ }^{1} \mathrm{H}$ NMR $\left(300 \mathrm{MHz}, \mathrm{CDCl}_{3}\right)$ : $\delta(\mathrm{ppm}) 1.94(\mathrm{t}, J=6.21 \mathrm{~Hz}, 1 \mathrm{H}, \mathrm{OH}), 3.84-4.08\left(\mathrm{~m}, 2 \mathrm{H}, \mathrm{CH}_{2} \mathrm{OH}\right)$, $4.12-4.28(\mathrm{~m}, 1 \mathrm{H}, \mathrm{CH}), 4.28-4.49\left(\mathrm{~m}, 2 \mathrm{H}, \mathrm{CH}_{2} \mathrm{O}\right), 6.94-7.02(\mathrm{~m}, 1 \mathrm{H}$, $\left.\mathrm{Ar}-\mathrm{H}^{5}\right), 7.74-7.87\left(\mathrm{~m}, 2 \mathrm{H}, \mathrm{Ar}-\mathrm{H}^{6}, \mathrm{Ar}-\mathrm{H}^{8}\right)$.

\subsection{Synthesis of (S)-(7-nitro-2,3-dihydro-1,4-benzodioxin-2-yl) methanol (5d)}

A suspension of 4-nitrocatechol (310 $\mathrm{mg}, 2.00 \mathrm{mmol}$ ), (R)-glycidyl tosylate $\left(545 \mathrm{mg}, 2.40 \mathrm{mmol}\right.$ ) and $\mathrm{K}_{2} \mathrm{CO}_{3}(663 \mathrm{mg}, 4.80 \mathrm{mmol})$ in $5 \mathrm{~mL} \mathrm{DMF}$ was heated at $60^{\circ} \mathrm{C}$ for $2 \mathrm{~h}$. The mixture was poured onto $15 \mathrm{~mL}$ water and extracted with $4 \times 20 \mathrm{~mL}$ diethyl ether. The combined organic phases were subsequently washed with $3 \times 20 \mathrm{~mL} 10 \%$ aq. $\mathrm{K}_{2} \mathrm{CO}_{3}, 20 \mathrm{~mL}$ water and $20 \mathrm{~mL}$ brine. The organic layer was dried over $\mathrm{Na}_{2} \mathrm{SO}_{4}$, filtered and evaporated to dryness. The crude product obtained was purified by column cromatography (petrolether:ethyl acetate $=1: 1$ ) to give $180 \mathrm{mg}$ of yellow crystals (43\%); mp 117-119 ${ }^{\circ} \mathrm{C} ;[\alpha]_{\mathrm{D}}=-61.6\left(c=0.5\right.$ in $\left.\mathrm{CHCl}_{3}\right) ;{ }^{1} \mathrm{H}$ NMR (300 MHz, $\left.\mathrm{CDCl}_{3}\right): \delta(\mathrm{ppm}) 1.93(\mathrm{t}, J=6.19 \mathrm{~Hz}, 1 \mathrm{H}, \mathrm{OH}), 3.86-4.04$ $\left(\mathrm{m}, 2 \mathrm{H}, \mathrm{CH}_{2} \mathrm{OH}\right), 4.13-4.27(\mathrm{~m}, 1 \mathrm{H}, \mathrm{CH}), 4.30-4.47\left(\mathrm{~m}, 2 \mathrm{H}, \mathrm{CH}_{2} \mathrm{O}\right)$, 6.93-7.03 (m, 1H, Ar- $\left.\mathrm{H}^{5}\right), 7.75-7.86\left(\mathrm{~m}, 2 \mathrm{H}, \mathrm{Ar}-\mathrm{H}^{6}, \mathrm{Ar}-\mathrm{H}^{8}\right)$.

\section{8. (R)-4-((6-nitro-2,3-dihydro-1,4-benzodioxin-2-yl)methoxy) benzonitrile $(\mathbf{6 a})$. General procedure for synthesis of compounds 6a-d}

The benzodioxine alcohol 5a $(2.80 \mathrm{~g}, 13.26 \mathrm{mmol})$ was dissolved in anhydrous THF (50 mL). Under argon flow and with ice/water cooling, 4-cyanophenol (1.74 g, $14.59 \mathrm{mmol})$ and triphenylphosphine (6.96 g, $26.52 \mathrm{mmol}$ ) were added. Diizopropyl azodicarboxylate (DIAD) (5.36 g, $26.52 \mathrm{mmol}$ ) dissolved in $15 \mathrm{~mL}$ anhydrous THF was added dropwise at $0{ }^{\circ} \mathrm{C}$. The solution was stirred for $30 \mathrm{~min}$ at $0^{\circ} \mathrm{C}$, and then heated to reflux for $48 \mathrm{~h}$. The mixture was evaporated to dryness and the crude product was purified by recrystallization from $\mathrm{MeOH}$ to give $2.15 \mathrm{~g}(52 \%)$ of $\mathbf{6 a}$ as pale yellow crystals; mp $159-162{ }^{\circ} \mathrm{C} ;[\alpha]_{\mathrm{D}}=+83.4\left(c=0.5\right.$ in $\left.\mathrm{CDCl}_{3}\right) ;{ }^{1} \mathrm{H}$ NMR (400 MHz, DMSO-d $\left.{ }_{6}\right): \delta(\mathrm{ppm}) 4.28(\mathrm{dd}, J=11.8,7.2 \mathrm{~Hz}, 1 \mathrm{H}, 3-$ $\left.\mathrm{CH}_{2}\right), 4.39$ (dd, $\left.J=11.1,5.7 \mathrm{~Hz}, 1 \mathrm{H}, \mathrm{CH}_{2} \mathrm{O}\right), 4.46(\mathrm{dd}, J=11.1,3.7 \mathrm{~Hz}$, $\left.1 \mathrm{H}, \mathrm{CH}_{2} \mathrm{O}\right), 4.58\left(\mathrm{dd}, J=11.8,2.5 \mathrm{~Hz}, 1 \mathrm{H}, 3-\mathrm{CH}_{2}\right), 4.77-4.85(\mathrm{~m}, 1 \mathrm{H}$, 2-CH), 7.13-7.22 (m, 3H, $\left.\mathrm{Ar}-\mathrm{H}^{8}, \mathrm{Ar}-\mathrm{H}^{2}, \mathrm{Ar}-\mathrm{H}^{6}\right), 7.77-7.84(\mathrm{~m}, 4 \mathrm{H}$, $\left.\mathrm{Ar}-\mathrm{H}^{5}, \mathrm{Ar}-\mathrm{H}^{7}, \mathrm{Ar}-\mathrm{H}^{3}, \mathrm{Ar}-\mathrm{H}^{5^{\prime}}\right) ;{ }^{13} \mathrm{C}$ NMR (101 MHz, DMSO-d 6 ): $\delta(\mathrm{ppm}) 64.4(\mathrm{C}-3), 66.5\left(\mathrm{CH}_{2} \mathrm{O}\right), 72.2(\mathrm{C}-2), 103.4\left(\mathrm{C}-4^{\prime}\right), 112.7(\mathrm{C}-7)$, $115.6\left(\mathrm{C}-2^{\prime}, \mathrm{C}-6^{\prime}\right), 117.6,117.7(\mathrm{C}-5, \mathrm{C}-8), 119.0(\mathrm{CN}), 134.2\left(\mathrm{C}-3^{\prime}, \mathrm{C}-5^{\prime}\right)$, 141.1 (C-6), 142.7 (C-4a), 148.8 (C-8a), 161.4 (C-1'); HRMS (ESI) m/z calcd for $\mathrm{C}_{16} \mathrm{H}_{13} \mathrm{~N}_{2} \mathrm{O}_{5}[\mathrm{M}+\mathrm{H}]^{+}$313.0824, found 313.0830; IR (KBr, $v$, $\left.\mathrm{cm}^{-1}\right): 222,1605,1522,1471,1347,1252,1174,839 ;$ HPLC: $100 \%, t_{\mathrm{r}}$ 16.0 min; Anal. $\left(\mathrm{C}_{16} \mathrm{H}_{12} \mathrm{~N}_{2} \mathrm{O}_{5}\right) \mathrm{C}, \mathrm{H}, \mathrm{N}$.

\section{9. (S)-4-((6-nitro-2,3-dihydro-1,4-benzodioxin-2-yl)methoxy) benzonitrile $(\boldsymbol{6 b})$}

Synthesized from $\mathbf{5 b}(1.17 \mathrm{~g}, 5.54 \mathrm{mmol})$ according to the general procedure for synthesis of compounds $\mathbf{6 a}-\mathbf{d}$; pale yellow crystals, yield $865 \mathrm{mg}(50 \%) ; \mathrm{mp} 172-175^{\circ} \mathrm{C} ;[\alpha]_{\mathrm{D}}=-80.4(c=0.5$, $\left.\mathrm{CDCl}_{3}\right) ;{ }^{1} \mathrm{H}$ NMR $\left(400 \mathrm{MHz}, \mathrm{DMSO}-\mathrm{d}_{6}\right): \delta(\mathrm{ppm}) 4.33$ (dd, $J=11.7$, $\left.7.3 \mathrm{~Hz}, 1 \mathrm{H}, 3-\mathrm{CH}_{2}\right), 4.38\left(\mathrm{dd}, J=11.1,5.6 \mathrm{~Hz}, 1 \mathrm{H}, \mathrm{CH}_{2} \mathrm{O}\right), 4.45(\mathrm{dd}$, $\left.J=11.1,3.7 \mathrm{~Hz}, 1 \mathrm{H}, \mathrm{CH}_{2} \mathrm{O}\right), 4.62\left(\mathrm{dd}, J=11.7,2.5 \mathrm{~Hz}, 1 \mathrm{H}, 3-\mathrm{CH}_{2}\right.$ ), 4.72-4.78 (m, 1H, 2-CH), 7.11-7.23 (m, 3H, Ar- $\left.\mathrm{H}^{8}, \mathrm{Ar}-\mathrm{H}^{2}, \mathrm{Ar}-\mathrm{H}^{6^{\prime}}\right)$, 7.76-7.84 (m, 4H, Ar- $\left.\mathrm{H}^{5}, \mathrm{Ar}-\mathrm{H}^{7}, \mathrm{Ar}-\mathrm{H}^{3}, \mathrm{Ar}-\mathrm{H}^{5}\right) ;{ }^{13} \mathrm{C} \mathrm{NMR}$ (101 MHz, DMSO-d $\left.{ }_{6}\right): \delta(\mathrm{ppm}) 65.0(\mathrm{C}-3), 66.5\left(\mathrm{CH}_{2} \mathrm{O}\right), 71.4(\mathrm{C}-2)$, 103.4 (C-4'), 112.7 (C-7), 115.7 (C-2', C-6'), 117.5, 117.6 (C-5, C-8), $119.0(\mathrm{CN}), 134.2\left(\mathrm{C}-3^{\prime}, \mathrm{C}^{\prime} 5^{\prime}\right), 141.2$ (C-6), 142.4, 149.0 (C-4a, C-8a), $161.4\left(\mathrm{C}-1^{\prime}\right)$; HRMS (ESI) $m / z$ calcd for $\mathrm{C}_{16} \mathrm{H}_{13} \mathrm{~N}_{2} \mathrm{O}_{5}[\mathrm{M}+\mathrm{H}]^{+}$ 313.0824, found 313.0813; IR $\left(\mathrm{KBr}, v, \mathrm{~cm}^{-1}\right)$ : 2227, 1603, 1514, 1349 , 1256, 1174, 839; HPLC: $100 \%, t_{\mathrm{r}} 16.0 \mathrm{~min}$; Anal. $\left(\mathrm{C}_{16} \mathrm{H}_{12} \mathrm{~N}_{2} \mathrm{O}_{5}\right) \mathrm{C}, \mathrm{H}, \mathrm{N}$. 
6.10. (R)-4-((7-nitro-2,3-dihydro-1,4-benzodioxin-2-yl)methoxy) benzonitrile $(\mathbf{6 c})$

Synthesized from $\mathbf{5 c}(1.17 \mathrm{~g}, 5.54 \mathrm{mmol})$ according to the general procedure for synthesis of compounds $\mathbf{6 a}-\mathbf{d}$; pale yellow crystals, yield $865 \mathrm{mg}(50 \%)$; $\mathrm{mp} 159-162{ }^{\circ} \mathrm{C} ;[\alpha]_{\mathrm{D}}=-29.7\left(c=0.5, \mathrm{CDCl}_{3}\right)$; ${ }^{1} \mathrm{H}$ NMR (400 MHz, DMSO-d $): \delta(\mathrm{ppm}) 4.33(\mathrm{dd}, J=11.7,7.3 \mathrm{~Hz}, 1 \mathrm{H}$, $\left.3-\mathrm{CH}_{2}\right), 4.38\left(\mathrm{dd}, J=11.2,5.7 \mathrm{~Hz}, 1 \mathrm{H}, \mathrm{CH}_{2} \mathrm{O}\right), 4.45(\mathrm{dd}, J=11.2,3.7 \mathrm{~Hz}$, $\left.1 \mathrm{H}, \mathrm{CH}_{2} \mathrm{O}\right), 4.62\left(\mathrm{dd}, J=11.7,2.5 \mathrm{~Hz}, 1 \mathrm{H}, 3-\mathrm{CH}_{2}\right), 4.71-4.79(\mathrm{~m}, 1 \mathrm{H}, 2-$ $\mathrm{CH}), 7.14-7.21\left(\mathrm{~m}, 3 \mathrm{H}, \mathrm{Ar}-\mathrm{H}^{5}, \mathrm{Ar}-\mathrm{H}^{2}, \mathrm{Ar}-\mathrm{H}^{6^{\prime}}\right), 7.75-7.85(\mathrm{~m}, 4 \mathrm{H}$, $\left.\mathrm{Ar}-\mathrm{H}^{6}, \mathrm{Ar}-\mathrm{H}^{8}, \mathrm{Ar}-\mathrm{H}^{3^{\prime}}, \mathrm{Ar}-\mathrm{H}^{5^{\prime}}\right) ;{ }^{13} \mathrm{C}$ NMR (101 MHz, DMSO-d 6 ): $\delta(\mathrm{ppm}) 65.0(\mathrm{C}-3), 66.5\left(\mathrm{CH}_{2} \mathrm{O}\right), 71.4(\mathrm{C}-2), 103.4\left(\mathrm{C}-4^{\prime}\right), 112.7(\mathrm{C}-6)$, 115.7 (C-2', C-6'), 117.5, 117.6 (C-5, C-8), 119.0 (CN), $134.2\left(\mathrm{C}^{\prime} 3^{\prime}, \mathrm{C}-5^{\prime}\right)$, 141.2 (C-7), 142.5, 149.0 (C-4a, C-8a), 161.4 (C-1'); HRMS (ESI) $m / z$ calcd for $\mathrm{C}_{16} \mathrm{H}_{13} \mathrm{~N}_{2} \mathrm{O}_{5}[\mathrm{M}+\mathrm{H}]^{+}$313.0824, found 313.0827; IR ( KBr, $v$, $\left.\mathrm{cm}^{-1}\right): 2227,1605,1515,1457,1350,1256,1175,839$; HPLC: $100 \%, t_{\mathrm{r}}$ 16.0 min; Anal. $\left(\mathrm{C}_{16} \mathrm{H}_{12} \mathrm{~N}_{2} \mathrm{O}_{5}\right) \mathrm{C}, \mathrm{H}, \mathrm{N}$.

\subsection{1. (S)-4-((7-nitro-2,3-dihydro-1,4-benzodioxin-2-yl)methoxy)} benzonitrile $(\mathbf{6 d})$

Synthesized from $5 \mathbf{d}(1.17 \mathrm{~g}, 5.54 \mathrm{mmol})$ according to the general procedure for synthesis of compounds $\mathbf{6 a}-\mathbf{d}$; pale yellow crystals, yield $830 \mathrm{mg}(48 \%) ; \mathrm{mp} 168-171{ }^{\circ} \mathrm{C} ;[\alpha]_{\mathrm{D}}=+30.2(c=0.5$, $\mathrm{CHCl}_{3}$ ); ${ }^{1} \mathrm{H}$ NMR (400 MHz, DMSO-d 6 ): $\delta(\mathrm{ppm}) 4.33$ (dd, $J=11.7$, $7.3 \mathrm{~Hz}, 1 \mathrm{H}, 3-\mathrm{CH}_{2}$ ), 4.38 (dd, $J=11.1,5.7 \mathrm{~Hz}, 1 \mathrm{H}, \mathrm{CH}_{2} \mathrm{O}$ ), 4.45 (dd, $\left.J=11.1,3.7 \mathrm{~Hz}, 1 \mathrm{H}, \mathrm{CH}_{2} \mathrm{O}\right), 4.62\left(\mathrm{dd}, J=11.7,2.5 \mathrm{~Hz}, 1 \mathrm{H}, 3-\mathrm{CH}_{2}\right)$, 4.68-4.81 (m, 1H, 2-CH), 7.11-7.23 (m, 3H, $\left.\mathrm{Ar}-\mathrm{H}^{5}, \mathrm{Ar}-\mathrm{H}^{2}, \mathrm{Ar}-\mathrm{H}^{6^{\prime}}\right)$, 7.74-7.85 (m, 4H, $\left.\mathrm{Ar}-\mathrm{H}^{6}, \mathrm{Ar}-\mathrm{H}^{8}, \mathrm{Ar}-\mathrm{H}^{3}, \mathrm{Ar}-\mathrm{H}^{5^{\prime}}\right) ;{ }^{13} \mathrm{C} \mathrm{NMR}$ (101 MHz, DMSO-d 6 ): $\delta(\mathrm{ppm}) 64.9(\mathrm{C}-3), 66.5\left(\mathrm{CH}_{2} \mathrm{O}\right), 71.4(\mathrm{C}-2)$, $103.4\left(\mathrm{C}-4^{\prime}\right), 112.7$ (C-6), 115.7 (C-2', C-6'), 117.5, 117.6 (C-5, C8), 119.0 (CN), 134.2 (C-3', C-5'), 141.2 (C-7), 142.5, 149.0 (C-4a, C8a), $161.4\left(\mathrm{C}-1^{\prime}\right)$; HRMS (ESI) $m / z$ calcd for $\mathrm{C}_{16} \mathrm{H}_{13} \mathrm{~N}_{2} \mathrm{O}_{5}[\mathrm{M}+\mathrm{H}]^{+}$ 313.0824, found 313.0833; IR (KBr, $\left.v, \mathrm{~cm}^{-1}\right)$ : 2225, 1600, 1504, 1349, 1251, 820; HPLC: $100 \%, t_{\mathrm{r}} 16.0 \mathrm{~min}$; Anal. $\left(\mathrm{C}_{16} \mathrm{H}_{12} \mathrm{~N}_{2} \mathrm{O}_{5}\right)$ C, H, N.

6.12. (R)-4-((6-(benzylamino)-2,3-dihydro-1,4-benzodioxin-2-yl) methoxy)benzonitrile (8a). General procedure for synthesis of compounds $8 \boldsymbol{8}-\boldsymbol{d}$

To a solution of compound $\mathbf{6 a}(800 \mathrm{mg}, 2.56 \mathrm{mmol})$ in $100 \mathrm{~mL}$ $\mathrm{MeOH}, 10 \% \mathrm{Pd} / \mathrm{C}(80 \mathrm{mg}$ ) was added and the mixture was stirred in a hydrogenator at 25 bar for $1 \mathrm{~h}$ till the reaction was completed. The catalyst was filtered off and the solvent was evaporated in vacuo to yield $720 \mathrm{mg}$ (100\%) of 7a which was used in the next step without purification. To a solution of the crude amine 7a (722 mg, $2.56 \mathrm{mmol})$ in methanol ( $50 \mathrm{~mL}$ ) containing molecular sieves under argon atmosphere, benzaldehyde (406 mg, $3.83 \mathrm{mmol}$ ) was added and the mixture was stirred at room temperature for $12 \mathrm{~h}$, until the aldimine formation was completed. The reaction mixture containing aldimine in methanol was carefully treated with $\mathrm{NaBH}_{4}$ (154 mg, $4.08 \mathrm{mmol}$ ) and stirred for additional $1 \mathrm{~h}$, filtered, and the solvent was evaporated in vacuo. The crude residue was dissolved in dichloromethane $(50 \mathrm{~mL})$ and washed successively with saturated $\mathrm{NaHCO}_{3}$ solution $(3 \times 50 \mathrm{~mL})$ and brine $(1 \times 50 \mathrm{~mL})$. The organic phase was dried over $\mathrm{Na}_{2} \mathrm{SO}_{4}$ and the solvent evaporated under reduced pressure. The oily product was purified by column chromatography using dichloromethane as eluant to obtain $439 \mathrm{mg}$ (46\%) of 8a as yellow crystals; mp $144-147{ }^{\circ} \mathrm{C}$; $[\alpha]_{\mathrm{D}}=+32.4$ $\left(c=0.5, \mathrm{CHCl}_{3}\right) ;{ }^{1} \mathrm{H}$ NMR $\left(400 \mathrm{MHz}, \mathrm{DMSO}-\mathrm{d}_{6}\right): \delta(\mathrm{ppm}) 4.05(\mathrm{dd}$, $\left.J=11.4,7.9 \mathrm{~Hz}, 1 \mathrm{H}, 3-\mathrm{CH}_{2}\right), 4.18\left(\mathrm{~s}, 2 \mathrm{H}, \mathrm{NCH}_{2}\right), 4.22-4.36(\mathrm{~m}, 3 \mathrm{H}, 3-$ $\left.\mathrm{CH}_{2}, \mathrm{CH}_{2} \mathrm{O}\right), 4.38-4.47(\mathrm{~m}, 1 \mathrm{H}, 2-\mathrm{CH}), 5.92(\mathrm{bs}, 1 \mathrm{H}, \mathrm{NH}), 6.09$ (d, $\left.J=2.6 \mathrm{~Hz}, 1 \mathrm{H}, \mathrm{Ar}-\mathrm{H}^{5}\right), 6.15\left(\mathrm{dd}, J=8.7,2.6 \mathrm{~Hz}, 1 \mathrm{H}, \mathrm{Ar}-\mathrm{H}^{7}\right), 6.62(\mathrm{~d}$, $\left.J=8.7 \mathrm{~Hz}, 1 \mathrm{H}, \mathrm{Ar}-\mathrm{H}^{8}\right), 7.16\left(\mathrm{~d}, J=9.0 \mathrm{~Hz}, 2 \mathrm{H}, \mathrm{Ar}-\mathrm{H}^{2}, \mathrm{Ar}-\mathrm{H}^{6^{\prime}}\right), 7.19-$
7.25 (m, 1H, Ph), 7.27-7.39 (m, 4H, Ph), 7.78 (d, $J=9.0 \mathrm{~Hz}, 2 \mathrm{H}, \mathrm{Ar}-$ $\left.\mathrm{H}^{3}, \mathrm{Ar}-\mathrm{H}^{5}\right) ;{ }^{13} \mathrm{C}$ NMR (101 MHz, DMSO-d 6 ): $\delta(\mathrm{ppm}) 47.0\left(\mathrm{Ph}-\mathrm{CH}_{2}\right)$, 64.7 (C-3), $66.9\left(\mathrm{CH}_{2} \mathrm{O}\right), 70.7$ (C-2), $100.4(\mathrm{C}-5), 103.2\left(\mathrm{C}-4^{\prime}\right), \overline{106.5}$ (C-7), 115.6 (C-2', C-6'), $117.2(\mathrm{C}-8), 119.0(\mathrm{CN}), 126.5\left(\mathrm{C}-4^{\prime \prime}\right), 127.1(\mathrm{C}-$ $\left.2^{\prime \prime}, C^{\prime \prime} 6^{\prime \prime}\right), 128.2\left(C-3^{\prime \prime}, C-5^{\prime \prime}\right), 133.3(C-8 a), 134.2\left(C-3^{\prime}, C-5^{\prime}\right), 140.4(C-$ 6), 143.0 (C-1"), 143.7 (C-4a), 161.6 (C-1'); HRMS (ESI) $\mathrm{m} / z$ calcd for $\mathrm{C}_{23} \mathrm{H}_{21} \mathrm{~N}_{2} \mathrm{O}_{3}[\mathrm{M}+\mathrm{H}]^{+}$373. 1552, found 373.1547; IR $\left(\mathrm{KBr}, v, \mathrm{~cm}^{-1}\right)$ : $3378,2221,1508,1250,1176,828$; HPLC: $100 \%, t_{\mathrm{r}} 11.7 \mathrm{~min}$; Anal. $\left(\mathrm{C}_{23} \mathrm{H}_{20} \mathrm{~N}_{2} \mathrm{O}_{3}\right) \mathrm{C}, \mathrm{H}, \mathrm{N}$.

\subsection{3. (S)-4-((6-(benzylamino)-2,3-dihydro-1,4-benzodioxin-2-yl) methoxy)benzonitrile ( $8 \boldsymbol{b})$}

Synthesized from $\mathbf{6 b}(800 \mathrm{mg}, 2.56 \mathrm{mmol})$ according to the general procedure for synthesis of compounds $8 \mathbf{a}-\mathbf{d}$; yellow crystals, yield $439 \mathrm{mg}(46 \%) ; \mathrm{mp} 88-91{ }^{\circ} \mathrm{C} ;[\alpha]_{\mathrm{D}}=-32.8(c=0.5$ in $\left.\mathrm{CHCl}_{3}\right) ;{ }^{1} \mathrm{H}$ NMR (400 MHz, DMSO-d 6 ): $\delta$ (ppm) 4.00 (dd, $\left.J=11.4,7.2 \mathrm{~Hz}, 1 \mathrm{H}, 3-\mathrm{CH}_{2}\right), 4.18\left(\mathrm{~d}, J=5.9 \mathrm{~Hz}, 2 \mathrm{H}, \mathrm{NCH}_{2}\right)$, 4.23-4.35 (m, 3H, 3- $\left.\mathrm{CH}_{2}, \mathrm{CH}_{2} \mathrm{O}\right), 4.44-4.55(\mathrm{~m}, 1 \mathrm{H}, 2-\mathrm{CH}), 5.93$ (bt, $J=6.1 \mathrm{~Hz}, 1 \mathrm{H}, \mathrm{NH}), 6.07\left(\mathrm{~d}, J=2.6 \mathrm{~Hz}, 1 \mathrm{H}, \mathrm{Ar}-\mathrm{H}^{5}\right), 6.15(\mathrm{dd}, J=8.7$, $\left.2.7 \mathrm{~Hz}, 1 \mathrm{H}, \mathrm{Ar}-\mathrm{H}^{7}\right), 6.62\left(\mathrm{~d}, J=8.7 \mathrm{~Hz}, 1 \mathrm{H}, \mathrm{Ar}-\mathrm{H}^{8}\right), 7.16(\mathrm{~d}$, $\left.J=9.0 \mathrm{~Hz}, 2 \mathrm{H}, \mathrm{Ar}-\mathrm{H}^{2}, \mathrm{Ar}-\mathrm{H}^{6^{\prime}}\right), 7.19-7.26(\mathrm{~m}, 1 \mathrm{H}, \mathrm{Ph}), 7.28-7.37$ $(\mathrm{m}, 4 \mathrm{H}, \mathrm{Ph}), 7.78\left(\mathrm{~d}, J=9.0 \mathrm{~Hz}, 2 \mathrm{H}, \mathrm{Ar}-\mathrm{H}^{3}, \mathrm{Ar}-\mathrm{H}^{5}\right) ;{ }^{13} \mathrm{C} \mathrm{NMR}$ $\left(101 \mathrm{MHz}\right.$, DMSO-d 6 ): $\delta(\mathrm{ppm}) 47.0\left(\mathrm{Ph}-\mathrm{CH}_{2}\right), 64.2(\mathrm{C}-3), 66.9$ $\left(\mathrm{CH}_{2} \mathrm{O}\right.$ ), 71.4 (C-2), 100.3 (C-5), $103.2\left(\mathrm{C}-4^{\prime}\right), 106.3$ (C-7), 115.6 (C-2', C-6'), 117.1 (C-8), $119.0(\mathrm{CN}), 126.4\left(\mathrm{C}-4^{\prime \prime}\right), 127.1\left(\mathrm{C}-2^{\prime \prime}, \mathrm{C}-6^{\prime \prime}\right), 128.2$ (C-3", C-5"'), 133.6 (C-8a), 134.2 (C-3', C-5'), 140.4 (C-6), 142.7 (C$1^{\prime \prime}$ ), 143.9 (C-4a), 161.6 (C-1'); HRMS (ESI) $\mathrm{m} / z$ calcd for $\mathrm{C}_{23} \mathrm{H}_{21} \mathrm{~N}_{2} \mathrm{O}_{3}$ $[\mathrm{M}+\mathrm{H}]^{+}$373.1552, found 373.1534; IR $\left(\mathrm{KBr}, v, \mathrm{~cm}^{-1}\right): 2219,1606$, 1504, 1260, 1174, 1045, 830; HPLC: 98.1\%, $t_{\mathrm{r}} 11.7 \mathrm{~min}$; Anal. $\left(\mathrm{C}_{23} \mathrm{H}_{20} \mathrm{~N}_{2} \mathrm{O}_{3}\right) \mathrm{C}, \mathrm{H}, \mathrm{N}$.

\subsection{4. (R)-4-((7-(benzylamino)-2,3-dihydro-1,4-benzodioxin-2-yl) methoxy)benzonitrile $(\mathbf{8 c})$}

Synthesized from $\mathbf{6 c}(800 \mathrm{mg}, 2.56 \mathrm{mmol})$ according to the general procedure for synthesis of compounds 8a-d; yellow crystals, yield $420 \mathrm{mg}$ (44\%); mp $111-114{ }^{\circ} \mathrm{C}$; $[\alpha]_{\mathrm{D}}=-42.5$ $\left(c=0.8, \mathrm{CDCl}_{3}\right) ;{ }^{1} \mathrm{H}$ NMR (400 MHz, DMSO-d 6 ): $\delta(\mathrm{ppm}) 4.00$ (dd, $\left.J=11.5,7.2 \mathrm{~Hz}, 1 \mathrm{H}, 3-\mathrm{CH}_{2}\right), 4.18\left(\mathrm{~d}, J=4.8 \mathrm{~Hz}, 2 \mathrm{H}, \mathrm{NCH}_{2}\right)$, $4.22-4.35\left(\mathrm{~m}, 3 \mathrm{H}, 3-\mathrm{CH}_{2}, \mathrm{CH}_{2} \mathrm{O}\right), 4.43-4.57(\mathrm{~m}, 1 \mathrm{H}, 2-\mathrm{CH}), 5.93$ (bt, $J=5.6 \mathrm{~Hz}, 1 \mathrm{H}, \mathrm{NH}), 6.07\left(\mathrm{~d}, J=2.6 \mathrm{~Hz}, 1 \mathrm{H}, \mathrm{Ar}-\mathrm{H}^{8}\right), 6.15(\mathrm{dd}$, $\left.J=8.7,2.6 \mathrm{~Hz}, 1 \mathrm{H}, \mathrm{Ar}-\mathrm{H}^{6}\right), 6.62\left(\mathrm{~d}, J=8.7 \mathrm{~Hz}, 1 \mathrm{H}, \mathrm{Ar}-\mathrm{H}^{5}\right), 7.16(\mathrm{~d}$, $\left.J=9.0 \mathrm{~Hz}, 2 \mathrm{H}, \mathrm{Ar}-\mathrm{H}^{2}, \mathrm{Ar}-\mathrm{H}^{6^{\prime}}\right), 7.19-7.25(\mathrm{~m}, 1 \mathrm{H}, \mathrm{Ph}), 7.27-7.38$ $(\mathrm{m}, 4 \mathrm{H}, \mathrm{Ph}), 7.78\left(\mathrm{~d}, J=9.0 \mathrm{~Hz}, 2 \mathrm{H}, \mathrm{Ar}-\mathrm{H}^{3^{\prime}}, \mathrm{Ar}-\mathrm{H}^{5^{\prime}}\right) ;{ }^{13} \mathrm{C} \mathrm{NMR}$ (101 MHz, DMSO-d 6 ): $\delta(\mathrm{ppm}) 47.0\left(\mathrm{Ph}-\mathrm{CH}_{2}\right) 64.2(\mathrm{C}-3), 66.7$ $\left(\mathrm{CH}_{2} \mathrm{O}\right), 71.4(\mathrm{C}-2), 100.3(\mathrm{C}-8), 103.2\left(\mathrm{C}-4^{\prime}\right), \overline{106.3}$ (C-6), 115.6 (C-2', C-6'), 117.1 (C-5), $119.0(\mathrm{CN}), 126.5\left(\mathrm{C}-4^{\prime \prime}\right), 127.1\left(\mathrm{C}-2^{\prime \prime}, \mathrm{C}-6^{\prime \prime}\right), 128.2$ (C-3", C-5"'), 133.6 (C-8a), 134.2 (C-3', C-5'), 140.4 (C-7), 142.7 (C$\left.1^{\prime \prime}\right), 143.9$ (C-4a), 161.6 (C-1'); HRMS (ESI) $\mathrm{m} / \mathrm{z}$ calcd for $\mathrm{C}_{23} \mathrm{H}_{21} \mathrm{~N}_{2} \mathrm{O}_{3}[\mathrm{M}+\mathrm{H}]^{+}$373. 1552, found 373.1545; IR $\left(\mathrm{KBr}, v, \mathrm{~cm}^{-1}\right)$ : 3387, 3050, 2220, 1508, 1262, 1174, 832; HPLC: 98.8\%, $t_{\mathrm{r}} 11.7 \mathrm{~min}$; Anal. $\left(\mathrm{C}_{23} \mathrm{H}_{20} \mathrm{~N}_{2} \mathrm{O}_{3}\right) \mathrm{C}, \mathrm{H}, \mathrm{N}$.

\subsection{5. (S)-4-((7-(benzylamino)-2,3-dihydro-1,4-benzodioxin-2-yl) methoxy)benzonitrile (8d)}

Synthesized from 7d (800 mg, $2.56 \mathrm{mmol})$ according to the general procedure for synthesis of compounds 8a-d; yellow crystals, yield $430 \mathrm{mg}(45 \%) ; \mathrm{mp} 86-89{ }^{\circ} \mathrm{C} ;[\alpha]_{\mathrm{D}}=+44.4(c=0.8$, $\left.\mathrm{CDCl}_{3}\right) ;{ }^{1} \mathrm{H}$ NMR $\left(400 \mathrm{MHz}, \mathrm{DMSO}-\mathrm{d}_{6}\right): \delta(\mathrm{ppm}) 4.00(\mathrm{dd}, J=11.4$, $\left.7.2 \mathrm{~Hz}, 1 \mathrm{H}, 3-\mathrm{CH}_{2}\right), 4.18\left(\mathrm{~d}, J=5.7 \mathrm{~Hz}, 2 \mathrm{H}, \mathrm{NCH}_{2}\right), 4.24-4.34(\mathrm{~m}, 3 \mathrm{H}$, $\left.3-\mathrm{CH}_{2}, \mathrm{CH}_{2} \mathrm{O}\right), 4.46-4.53(\mathrm{~m}, 1 \mathrm{H}, 2-\mathrm{CH}), 5.93$ (bt, $J=5.9 \mathrm{~Hz}, 1 \mathrm{H}$, $\mathrm{NH}), 6.07\left(\mathrm{~d}, J=2.6 \mathrm{~Hz}, 1 \mathrm{H}, \mathrm{Ar}-\mathrm{H}^{8}\right), 6.15(\mathrm{dd}, J=8.7,2.6 \mathrm{~Hz}$, $\left.1 \mathrm{H}, \mathrm{Ar}-\mathrm{H}^{6}\right), 6.62\left(\mathrm{~d}, J=8.7 \mathrm{~Hz}, 1 \mathrm{H}, \mathrm{Ar}-\mathrm{H}^{5}\right), 7.16(\mathrm{~d}, J=8.9 \mathrm{~Hz}, 2 \mathrm{H}$, 
$\left.\mathrm{Ar}-\mathrm{H}^{2^{\prime}}, \mathrm{Ar}-\mathrm{H}^{6^{\prime}}\right), 7.18-7.26(\mathrm{~m}, 1 \mathrm{H}, \mathrm{Ph}), 7.28-7.37$ ( $\left.\mathrm{m}, 4 \mathrm{H}, \mathrm{Ph}\right), 7.78$ $\left(\mathrm{d}, J=8.9 \mathrm{~Hz}, 2 \mathrm{H}, \mathrm{Ar}-\mathrm{H}^{3}, \mathrm{Ar}-\mathrm{H}^{5^{\prime}}\right) ;{ }^{13} \mathrm{C} \mathrm{NMR}\left(101 \mathrm{MHz}\right.$, DMSO- $\left.\mathrm{d}_{6}\right)$ : $\delta(\mathrm{ppm}) 47.0\left(\mathrm{Ph}-\mathrm{CH}_{2}\right), 64.2(\mathrm{C}-3), 66.9\left(\mathrm{CH}_{2} \mathrm{O}\right), 71.4(\mathrm{C}-2), 100.3$ (C-8), 103.2 (C-4'), 106.3 (C-6), 115.6 (C-2', C-6'), 117.1 (C-5), 119.0 (CN), $126.4\left(\mathrm{C}-4^{\prime \prime}\right), 127.1\left(\mathrm{C}-2^{\prime \prime}, \mathrm{C}-6^{\prime \prime}\right), 128.2\left(\mathrm{C}-3^{\prime \prime}, \mathrm{C}-5^{\prime \prime}\right), 133.6(\mathrm{C}-$ 8a), 134.2 (C-3', C-5'), 140.4 (C-7), 142.7 (C-1"'), 143.9 (C-4a), 161.6 $\left(\mathrm{C}-1^{\prime}\right)$; HRMS (ESI) $m / z$ calcd for $\mathrm{C}_{23} \mathrm{H}_{21} \mathrm{~N}_{2} \mathrm{O}_{3} \quad[\mathrm{M}+\mathrm{H}]^{+}$ 373.1552, found 373.1548; IR ( $\left.\mathrm{KBr}, v, \mathrm{~cm}^{-1}\right)$ : 3386, 3059, 2220, 1606, 1509, 1262, 1174, 832; HPLC: 93.6\%, $t_{\mathrm{r}} 11.8 \mathrm{~min}$; Anal. $\left(\mathrm{C}_{23} \mathrm{H}_{20} \mathrm{~N}_{2} \mathrm{O}_{3}\right) \mathrm{C}, \mathrm{H}, \mathrm{N}$.

6.16. (R)-ethyl 2-(benzyl(2-((4-cyanophenoxy)methyl)-2,3-dihydro1,4-benzodioxin-6-yl)amino)-2-oxoacetate (9a). General procedure for the synthesis of compounds $\mathbf{9 a}-\mathbf{d}$

Ethyl oxalyl chloride (185 mg, $1.35 \mathrm{mmol}$ ) was added to a solution of $8 \mathbf{a}(420 \mathrm{mg}, 1.13 \mathrm{mmol})$ and triethylamine $(136 \mathrm{mg}$, $1.35 \mathrm{mmol})$ in dichloromethane $(50 \mathrm{~mL})$ and the mixture was stirred for $2 \mathrm{~h}$. The solvent was removed under reduced pressure, the residue dissolved in ethyl acetate $(50 \mathrm{~mL})$ and washed successively with a $10 \%$ citric acid solution $(3 \times 50 \mathrm{~mL})$, saturated $\mathrm{NaHCO}_{3}$ solution $(3 \times 50 \mathrm{~mL})$ and brine $(1 \times 50 \mathrm{~mL})$. The organic phase was dried over $\mathrm{Na}_{2} \mathrm{SO}_{4}$ and the solvent evaporated under reduced pressure. The oily product was purified by column chromatography on silica gel using dichloromethane as eluant to obtain $497 \mathrm{mg}(93 \%)$ of $9 \mathrm{a}$ as pale yellow solid; $\mathrm{mp} 42-45^{\circ} \mathrm{C} ;[\alpha]_{\mathrm{D}}=+28.4$ $\left(c=0.5, \mathrm{CHCl}_{3}\right) ;{ }^{1} \mathrm{H}$ NMR $\left(400 \mathrm{MHz}, \mathrm{DMSO}-\mathrm{d}_{6}\right): \delta(\mathrm{ppm}) 0.93(\mathrm{t}$, $\left.J=7.1 \mathrm{~Hz}, 3 \mathrm{H}, \mathrm{CH}_{2} \underline{\mathrm{CH}}_{3}\right), 4.02$ (q, $\left.J=7.1 \mathrm{~Hz}, 2 \mathrm{H}, \underline{\mathrm{CH}_{2}} \mathrm{CH}_{3}\right), 4.13$ (dd, $\left.J=11.6,7.4 \mathrm{~Hz}, 1 \mathrm{H}, 3-\mathrm{CH}_{2}\right), 4.30\left(\mathrm{dd}, J=11.0,5.7 \mathrm{~Hz}, 1 \mathrm{H}, \mathrm{CH}_{2} \mathrm{O}\right), 4.37$ (dd, $J=11.0,3.7 \mathrm{~Hz}, 1 \mathrm{H}, \mathrm{CH}_{2} \mathrm{O}$ ), $4.44\left(\mathrm{dd}, J=11.6,2.4 \mathrm{~Hz}, 1 \mathrm{H}, 3-\mathrm{CH}_{2}\right.$ ), $4.56-4.64(\mathrm{~m}, 1 \mathrm{H}, 2-\mathrm{CH}), 4.90\left(\mathrm{~s}, 2 \mathrm{H}, \mathrm{NCH}_{2}\right), 6.62(\mathrm{dd}, J=8.6,2.7 \mathrm{~Hz}$, $\left.1 \mathrm{H}, \mathrm{Ar}-\mathrm{H}^{7}\right), 6.78\left(\mathrm{~d}, J=2.7 \mathrm{~Hz}, 1 \mathrm{H}, \mathrm{Ar}-\mathrm{H}^{5}\right), 6.89(\mathrm{~d}, J=8.6 \mathrm{~Hz}, 1 \mathrm{H}$, $\left.\mathrm{Ar}-\mathrm{H}^{8}\right), 7.15\left(\mathrm{~d}, J=9.0 \mathrm{~Hz}, 2 \mathrm{H}, \mathrm{Ar}-\mathrm{H}^{2}, \mathrm{Ar}-\mathrm{H}^{6^{\prime}}\right), 7.18-7.22(\mathrm{~m}, 2 \mathrm{H}$, $\mathrm{Ph}$ ), 7.27-7.37 (m, 3H, Ph), $7.79\left(\mathrm{~d}, J=9.0 \mathrm{~Hz}, 2 \mathrm{H}, \mathrm{Ar}-\mathrm{H}^{3}, \mathrm{Ar}-\mathrm{H}^{5^{\prime}}\right)$; ${ }^{13} \mathrm{C}$ NMR (101 MHz, DMSO-d $): \delta(\mathrm{ppm}) 13.4\left(\mathrm{CH}_{2}-\mathrm{CH}_{3}\right), 50.8(\mathrm{Ph}-$ $\left.\underline{\mathrm{CH}_{2}}\right), 61.3\left(\mathrm{CH}_{2}-\mathrm{CH}_{3}\right), 64.4(\mathrm{C}-3), 66.6\left(\mathrm{CH}_{2} \mathrm{O}\right), 71.3(\mathrm{C}-2), 103.3(\mathrm{C}-$ $\overline{\left.4^{\prime}\right)}, 115.6\left(\mathrm{C}-2^{\prime}, \mathrm{C}-6^{\prime}\right), 116.2(\mathrm{C}-7), 117.4(\mathrm{C}-5), 119.0(\mathrm{CN}), 120.9$ (C-8), $127.5\left(\mathrm{C}-4^{\prime \prime}\right), 128.0$ (C-2", C-6"), 128.6 (C-3", C-5" ), 132.3 (C-6), 134.2 $\left(\mathrm{C}-3^{\prime}, \mathrm{C}^{\prime} 5^{\prime}\right), 136.1\left(\mathrm{C}-1^{\prime \prime}\right), 142.6,142.7$ (C-4a, C-8a), 161.4, 161.5, 162.4 (CO-COO, CO-COO, C- $1^{\prime}$ ); HRMS (ESI) $m / z$ calcd for $\mathrm{C}_{27} \mathrm{H}_{25} \mathrm{~N}_{2} \mathrm{O}_{6}$ $[\overline{\mathrm{M}}+\mathrm{H}]^{+} 473.1713$, found 473.1706; IR $\left(\mathrm{KBr}, v, \mathrm{~cm}^{-1}\right)$ : 2224, 1605, 1507, 1252, 1175, 1016, 834; HPLC: 100\%, t $t_{\mathrm{r}} 17.6 \mathrm{~min}$; Anal. $\left(\mathrm{C}_{27} \mathrm{H}_{24} \mathrm{~N}_{2} \mathrm{O}_{6}\right) \mathrm{C}, \mathrm{H}, \mathrm{N}$.

\subsection{7. (S)-ethyl 2-(benzyl(2-((4-cyanophenoxy)methyl)-2,3-dihydro-} 1,4-benzodioxin-6-yl)amino)-2-oxoacetate (9b)

Synthesized from $\mathbf{8 b}$ (420 $\mathrm{mg}, 1.13 \mathrm{mmol}$ ) according to the general procedure for the synthesis of compounds $9 \mathbf{a}-\mathbf{d}$; pale yellow solid, yield $481 \mathrm{mg}$ (90\%); mp 41-44 ${ }^{\circ} \mathrm{C} ;[\alpha]_{\mathrm{D}}=-27.8$ $\left(c=0.5, \mathrm{CHCl}_{3}\right) ;{ }^{1} \mathrm{H}$ NMR $\left(400 \mathrm{MHz}, \mathrm{DMSO}-\mathrm{d}_{6}\right): \delta(\mathrm{ppm}) 0.90(\mathrm{t}$, $\left.J=7.1 \mathrm{~Hz}, 3 \mathrm{H}, \mathrm{CH}_{2} \mathrm{CH}_{3}\right), 4.00\left(\mathrm{q}, J=7.1 \mathrm{~Hz}, 2 \mathrm{H}, \underline{\mathrm{CH}_{2}} \mathrm{CH}_{3}\right), 4.14$ (dd, $\left.J=11.6,7.3 \mathrm{~Hz}, 1 \mathrm{H}, 3-\mathrm{CH}_{2}\right), 4.29\left(\mathrm{dd}, J=11.0,5.9 \mathrm{~Hz}, 1 \mathrm{H}, \mathrm{CH}_{2} \mathrm{O}\right), 4.37$ (dd, $J=11.0,3.5 \mathrm{~Hz}, 1 \mathrm{H}, \mathrm{CH}_{2} \mathrm{O}$ ), 4.44 (dd, $J=11.6,2.4 \mathrm{~Hz}, 1 \mathrm{H}, 3-\mathrm{CH}_{2}$ ), $4.56-4.63(\mathrm{~m}, 1 \mathrm{H}, 2-\mathrm{CH}), 4.90\left(\mathrm{~s}, 2 \mathrm{H}, \mathrm{NCH}_{2}\right), 6.62(\mathrm{dd}, J=8.6,2.5 \mathrm{~Hz}$, $\left.1 \mathrm{H}, \mathrm{Ar}-\mathrm{H}^{7}\right), 6.80\left(\mathrm{~d}, J=2.5 \mathrm{~Hz}, 1 \mathrm{H}, \mathrm{Ar}-\mathrm{H}^{5}\right), 6.88(\mathrm{~d}, J=8.6 \mathrm{~Hz}, 1 \mathrm{H}$, $\left.\mathrm{Ar}-\mathrm{H}^{8}\right), 7.16\left(\mathrm{~d}, J=9.0 \mathrm{~Hz}, 2 \mathrm{H}, \mathrm{Ar}-\mathrm{H}^{2}, \mathrm{Ar}-\mathrm{H}^{6^{\prime}}\right), 7.17-7.21(\mathrm{~m}, 2 \mathrm{H}$, $\mathrm{Ph}), 7.23-7.36(\mathrm{~m}, 3 \mathrm{H}, \mathrm{Ph}), 7.79\left(\mathrm{~d}, J=8.9 \mathrm{~Hz}, 2 \mathrm{H}, \mathrm{Ar}-\mathrm{H}^{3^{\prime}}, \mathrm{Ar}-\mathrm{H}^{5^{\prime}}\right)$; ${ }^{13} \mathrm{C}$ NMR (101 MHz, DMSO-d 6 ): $\delta(\mathrm{ppm}) 13.3\left(\mathrm{CH}_{2}-\mathrm{CH}_{3}\right), 50.8(\mathrm{Ph}-$ $\left.\underline{\mathrm{CH}_{2}}\right), 61.3\left(\underline{\mathrm{CH}}_{2}-\mathrm{CH}_{3}\right), 64.4(\mathrm{C}-3), 66.6\left(\mathrm{CH}_{2} \mathrm{O}\right), 71.3 \overline{(\mathrm{C}-2),} 103.3(\mathrm{C}-$ $\overline{\left.4^{\prime}\right)}, 115.6\left(\mathrm{C}-2^{\prime}, \mathrm{C}-6^{\prime}\right), 116.2(\mathrm{C}-7), 117.2(\mathrm{C}-5), 119.0(\mathrm{CN}), 120.7$ (C-8), $127.5\left(\mathrm{C}-4^{\prime \prime}\right), 127.9\left(\mathrm{C}-2^{\prime \prime}, \mathrm{C}-6^{\prime \prime}\right), 128.6\left(\mathrm{C}-3^{\prime \prime}, \mathrm{C}-5^{\prime \prime}\right), 132.5$ (C-6), 134.2 $\left(\mathrm{C}-3^{\prime}, \mathrm{C}-5^{\prime}\right), 136.1\left(\mathrm{C}-1^{\prime \prime}\right), 142.5,142.8$ (C-4a, C-8a), 161.4, 161.5, 162.4 (CO-COO, CO-COO, C- $1^{\prime}$ ); HRMS (ESI) $m / z$ calcd for $\mathrm{C}_{27} \mathrm{H}_{25} \mathrm{~N}_{2} \mathrm{O}_{6}$ $[\overline{\mathrm{M}}+\mathrm{H}]^{+} 473.1 \overline{713}$, found 473.1732; IR $\left(\mathrm{KBr}, v, \mathrm{~cm}^{-1}\right): 2225,1741$,
1669, 1606, 1507, 1256, 1172, 1028, 835; HPLC: 100\%, $t_{\mathrm{r}} 17.6 \mathrm{~min}$; Anal. $\left(\mathrm{C}_{27} \mathrm{H}_{24} \mathrm{~N}_{2} \mathrm{O}_{6}\right) \mathrm{C}, \mathrm{H}, \mathrm{N}$.

\subsection{8. (R)-ethyl 2-(benzyl(3-((4-cyanophenoxy)methyl)-2,3-dihydro-} 1,4-benzodioxin-7-yl)amino)-2-oxoacetate (9c)

Synthesized from $8 \mathbf{c}(420 \mathrm{mg}, 1.13 \mathrm{mmol}$ ) according to the general procedure for the synthesis of compounds $\mathbf{9 a}-\mathbf{d}$; pale yellow solid, yield $486 \mathrm{mg}(91 \%) ; \mathrm{mp} 43-46{ }^{\circ} \mathrm{C}$; $[\alpha]_{\mathrm{D}}=-14.2$ $\left(c=0.5, \mathrm{CHCl}_{3}\right) ;{ }^{1} \mathrm{H}$ NMR $\left(400 \mathrm{MHz}, \mathrm{DMSO}-\mathrm{d}_{6}\right): \delta(\mathrm{ppm}) 0.90(\mathrm{t}$, $\left.J=7.1 \mathrm{~Hz}, 3 \mathrm{H}, \mathrm{CH}_{2} \underline{\mathrm{CH}}_{3}\right), 4.00\left(\mathrm{q}, J=7.1 \mathrm{~Hz}, 2 \mathrm{H}, \underline{\mathrm{CH}_{2}} \mathrm{CH}_{3}\right), 4.14$ (dd, $\left.J=11.6,7.3 \mathrm{~Hz}, 1 \mathrm{H}, 3-\mathrm{CH}_{2}\right), 4.29\left(\mathrm{dd}, J=11.0,5.8 \mathrm{~Hz}, 1 \mathrm{H}, \mathrm{CH}_{2} \mathrm{O}\right), 4.37$ (dd, $\left.J=11.0,3.6 \mathrm{~Hz}, 1 \mathrm{H}, \mathrm{CH}_{2} \mathrm{O}\right), 4.44\left(\mathrm{dd}, J=11.6,2.4 \mathrm{~Hz}, 1 \mathrm{H}, 3-\mathrm{CH}_{2}\right.$ ), $4.55-4.64(\mathrm{~m}, 1 \mathrm{H}, 2-\mathrm{CH}), 4.90\left(\mathrm{~s}, 2 \mathrm{H}, \mathrm{NCH}_{2}\right), 6.62(\mathrm{dd}, J=8.6,2.6 \mathrm{~Hz}$, $\left.1 \mathrm{H}, \mathrm{Ar}-\mathrm{H}^{6}\right), 6.80\left(\mathrm{~d}, J=2.6 \mathrm{~Hz}, 1 \mathrm{H}, \mathrm{Ar}-\mathrm{H}^{8}\right), 6.88(\mathrm{~d}, J=8.6 \mathrm{~Hz}, 1 \mathrm{H}$, $\left.\mathrm{Ar}-\mathrm{H}^{5}\right), 7.16\left(\mathrm{~d}, J=9.0 \mathrm{~Hz}, 2 \mathrm{H}, \mathrm{Ar}-\mathrm{H}^{2}, \mathrm{Ar}-\mathrm{H}^{6^{\prime}}\right), 7.17-7.21(\mathrm{~m}, 2 \mathrm{H}$, $\mathrm{Ph}$ ), 7.25-7.35 (m, 3H, Ph), $7.80\left(\mathrm{~d}, J=9.0 \mathrm{~Hz}, 2 \mathrm{H}, \mathrm{Ar}-\mathrm{H}^{3^{\prime}}, \mathrm{Ar}-\mathrm{H}^{5^{\prime}}\right)$; ${ }^{13} \mathrm{C}$ NMR (101 MHz, DMSO-d 6$): \delta(\mathrm{ppm}) 13.3\left(\mathrm{CH}_{2}-\mathrm{CH}_{3}\right), 50.8(\mathrm{Ph}-$ $\left.\underline{\mathrm{CH}_{2}}\right), 61.3\left(\underline{\mathrm{CH}}_{2}-\mathrm{CH}_{3}\right), 64.4(\mathrm{C}-3), 66.6\left(\mathrm{CH}_{2} \mathrm{O}\right), 71.3 \overline{(\mathrm{C}-2)}, 103.3(\mathrm{C}-$ $\left.\overline{4^{\prime}}\right), 115.6\left(\mathrm{C}-2^{\prime}, \mathrm{C}-6^{\prime}\right), 116.2(\mathrm{C}-6), 117.2(\mathrm{C}-5), 119.0(\mathrm{CN}), 120.7(\mathrm{C}-8)$, $127.5\left(\mathrm{C}-4^{\prime \prime}\right), 127.9\left(\mathrm{C}-2^{\prime \prime}, \mathrm{C}-6^{\prime \prime}\right), 128.6\left(\mathrm{C}-3^{\prime \prime}, \mathrm{C}-5^{\prime \prime}\right), 132.5$ (C-7), 134.2 $\left(\mathrm{C}-3^{\prime}, \mathrm{C}-5^{\prime}\right), 136.1\left(\mathrm{C}-1^{\prime \prime}\right), 142.5,142.8$ (C-4a, C-8a), 161.4, 161.5, 162.4 (CO-COO, CO-COO, C- $1^{\prime}$ ); HRMS (EI) $m / z$ calcd for $\mathrm{C}_{27} \mathrm{H}_{25} \mathrm{~N}_{2} \mathrm{O}_{6}$ $[\overline{\mathrm{M}}+\mathrm{H}]^{+} 473.1713$, found 473.1718; IR $\left(\mathrm{KBr}, v, \mathrm{~cm}^{-1}\right): 2224,1741$, 1669, 1605, 1508, 1257, 1173, 1028, 834; HPLC: 100\%, $t_{\mathrm{r}} 17.5 \mathrm{~min}$; Anal. $\left(\mathrm{C}_{27} \mathrm{H}_{24} \mathrm{~N}_{2} \mathrm{O}_{6}\right) \mathrm{C}, \mathrm{H}, \mathrm{N}$.

\subsection{9. (S)-ethyl 2-(benzyl(3-((4-cyanophenoxy)methyl)-2,3-dihydro-} 1,4-benzodioxin-7-yl)amino)-2-oxoacetate (9d)

Synthesized from 8d (420 mg, $1.13 \mathrm{mmol}$ ) according to the general procedure for the synthesis of compounds $9 \mathbf{a}-\mathbf{d}$; pale yellow solid, yield $470 \mathrm{mg}(88 \%) ; \mathrm{mp} 45-48{ }^{\circ} \mathrm{C} ;[\alpha]_{\mathrm{D}}=+12.8$ $\left(c=0.5, \mathrm{CHCl}_{3}\right) ;{ }^{1} \mathrm{H}$ NMR $\left(400 \mathrm{MHz}, \mathrm{DMSO}-\mathrm{d}_{6}\right): \delta(\mathrm{ppm}) 0.93(\mathrm{t}$, $\left.J=7.1 \mathrm{~Hz}, 3 \mathrm{H}, \mathrm{CH}_{2} \underline{\mathrm{CH}}_{3}\right), 4.02\left(\mathrm{q}, J=7.1 \mathrm{~Hz}, 2 \mathrm{H}, \underline{\mathrm{CH}_{2}} \mathrm{CH}_{3}\right), 4.13$ (dd, $\left.J=11.6,7.4 \mathrm{~Hz}, 1 \mathrm{H}, \overline{3-\mathrm{CH}_{2}}\right), 4.30\left(\mathrm{dd}, J=11.0,5.8 \mathrm{~Hz}, 1 \mathrm{H}, \mathrm{CH}_{2} \mathrm{O}\right), 4.37$ (dd, $J=11.0,3.7 \mathrm{~Hz}, 1 \mathrm{H}, \mathrm{CH}_{2} \mathrm{O}$ ), 4.44 (dd, $J=11.6,2.4 \mathrm{~Hz}, 1 \mathrm{H}, 3-\mathrm{CH}_{2}$ ), 4.56-4.64 (m, $1 \mathrm{H}, 2-\mathrm{CH}), 4.90\left(\mathrm{~s}, 2 \mathrm{H}, \mathrm{NCH}_{2}\right), 6.62$ (dd, $J=8.6,2.5 \mathrm{~Hz}$, $\left.1 \mathrm{H}, \mathrm{Ar}-\mathrm{H}^{6}\right), 6.78\left(\mathrm{~d}, J=2.5 \mathrm{~Hz}, 1 \mathrm{H}, \mathrm{Ar}-\mathrm{H}^{8}\right), 6.89(\mathrm{~d}, J=8.6 \mathrm{~Hz}, 1 \mathrm{H}$, $\left.\mathrm{Ar}-\mathrm{H}^{5}\right), 7.15\left(\mathrm{~d}, J=9.0 \mathrm{~Hz}, 2 \mathrm{H}, \mathrm{Ar}-\mathrm{H}^{2}, \mathrm{Ar}-\mathrm{H}^{6^{\prime}}\right), 7.17-7.22(\mathrm{~m}, 2 \mathrm{H}$, $\mathrm{Ph}), 7.25-7.38(\mathrm{~m}, 3 \mathrm{H}, \mathrm{Ph}), 7.79\left(\mathrm{~d}, J=9.0 \mathrm{~Hz}, 2 \mathrm{H}, \mathrm{Ar}-\mathrm{H}^{3^{3}}, \mathrm{Ar}-\mathrm{H}^{5^{\prime}}\right)$; ${ }^{13} \mathrm{C}$ NMR (101 MHz, DMSO-d 6 ): $\delta(\mathrm{ppm}) 13.4\left(\mathrm{CH}_{2}-\mathrm{CH}_{3}\right), 50.8(\mathrm{Ph}-$ $\left.\underline{\mathrm{CH}_{2}}\right), 61.3\left(\underline{\mathrm{CH}}_{2}-\mathrm{CH}_{3}\right), 64.4(\mathrm{C}-3), 66.6\left(\mathrm{CH}_{2} \mathrm{O}\right), 71.3 \overline{(\mathrm{C}-2)}, 103.3(\mathrm{C}-$ $\overline{4^{\prime}}$ ), 115.6 (C-2', C-6'), 116.1 (C-6), $117.4(\mathrm{C}-5), 119.0(\mathrm{CN}), 120.9$ (C-8), $127.5\left(\mathrm{C}-4^{\prime \prime}\right), 128.0\left(\mathrm{C}-2^{\prime \prime}, \mathrm{C}-6^{\prime \prime}\right), 128.6\left(\mathrm{C}-3^{\prime \prime}, \mathrm{C}-5^{\prime \prime}\right), 132.3(\mathrm{C}-7), 134.2$ $\left(\mathrm{C}-3^{\prime}, \mathrm{C}-5^{\prime}\right), 136.1$ (C-1"' $), 142.6,142.7$ (C-4a, C-8a), 161.4, 161.5, 162.4 (CO-COO, CO-COO, C- $1^{\prime}$ ); HRMS (ESI) $m / z$ calcd for $\mathrm{C}_{27} \mathrm{H}_{25} \mathrm{~N}_{2} \mathrm{O}_{6}$ $[\overline{\mathrm{M}}+\mathrm{H}]^{+} 473.1713$, found 473.1704 ; IR $\left(\mathrm{KBr}, v, \mathrm{~cm}^{-1}\right): 2225,1741$, 1670, 1606, 1508, 1256, 1172, 1029, 835; HPLC: 100\%, $t_{\mathrm{r}} 17.5 \mathrm{~min}$; Anal. $\left(\mathrm{C}_{27} \mathrm{H}_{24} \mathrm{~N}_{2} \mathrm{O}_{6} \times 1 / 2 \mathrm{H}_{2} \mathrm{O}\right) \mathrm{C}, \mathrm{H}, \mathrm{N}$.

6.20. (R)-ethyl 2-(benzyl(2-((4-carbamimidoylphenoxy)methyl)-2,3dihydro-1,4-benzodioxin-6-yl)amino)-2-oxoacetate trifluoroacetate (10a). General procedure for synthesis of amidines $10 a-d$

Gaseous $\mathrm{HCl}$ was slowly introduced over $30 \mathrm{~min}$ into a solution of the nitrile $\mathbf{9 a}(480 \mathrm{mg}, 1.02 \mathrm{mmol})$ in anhydrous ethanol $(30 \mathrm{~mL})$. The reaction mixture was closed tightly and stirred for $24 \mathrm{~h}$ at room temperature. The solvent was evaporated in vacuo and the residue washed 3 times with anhydrous diethyl ether. Obtained iminoether was dissolved in anhydrous EtOH $(30 \mathrm{~mL})$, ammonium acetate $(3$ eq, $237 \mathrm{mg}, 3.06 \mathrm{mmol}$ ) was added and the reaction mixture stirred for $24 \mathrm{~h}$ at room temperature. The solvent was evaporated and crude product was purified by reverse phase column chromatography with gradient using methanol/trifluoroacetic acid (40-80\% 
in $30 \mathrm{~min}$ ) as eluant. After evaporation of methanol white crystals were precipitated from trifluoroacetic acid, filtered off and dried to yield $350 \mathrm{mg}$ (70\%) of 10a as a white powder; yield $350 \mathrm{mg}$ (58\%); mp 188-191 ${ }^{\circ} \mathrm{C} ;[\alpha]_{\mathrm{D}}=+31.4(c=0.5$, EtOH $) ;{ }^{1} \mathrm{H} \mathrm{NMR}(400 \mathrm{MHz}$, DMSO-d 6 ): $\delta(\mathrm{ppm}) 0.93\left(\mathrm{t}, J=7.1 \mathrm{~Hz}, 3 \mathrm{H}, \mathrm{CH}_{2} \mathrm{CH}_{3}\right), 4.02(\mathrm{q}$, $\left.J=7.1 \mathrm{~Hz}, 2 \mathrm{H}, \underline{\mathrm{CH}_{2}} \mathrm{CH}_{3}\right), 4.14\left(\mathrm{dd}, J=11.6,7.4 \mathrm{~Hz}, 1 \mathrm{H}, 3-\mathrm{CH}_{2}\right), 4.32$ $\left(\mathrm{dd}, J=11.0,5.8 \mathrm{~Hz}, 1 \mathrm{H}, \mathrm{CH}_{2} \mathrm{O}\right), 4.39\left(\mathrm{dd}, J=11.0,3.7 \mathrm{~Hz}, 1 \mathrm{H}, \mathrm{CH}_{2} \mathrm{O}\right)$, $4.46\left(\mathrm{dd}, J=11.6,2.4 \mathrm{~Hz}, 1 \mathrm{H}, 3-\mathrm{CH}_{2}\right), 4.57-4.65(\mathrm{~m}, 1 \mathrm{H}, 2-\mathrm{CH}), 4.90$ $\left(\mathrm{s}, 2 \mathrm{H}, \mathrm{NCH}_{2}\right), 6.63$ (dd, $\left.J=8.6,2.6 \mathrm{~Hz}, 1 \mathrm{H}, \mathrm{Ar}-\mathrm{H}^{7}\right), 6.79$ (d, $\left.J=2.6 \mathrm{~Hz}, 1 \mathrm{H}, \mathrm{Ar}-\mathrm{H}^{6}\right), 6.89\left(\mathrm{~d}, J=8.6 \mathrm{~Hz}, 1 \mathrm{H}, \mathrm{Ar}-\mathrm{H}^{8}\right), 7.17-7.24(\mathrm{~m}$, $\left.4 \mathrm{H}, \mathrm{Ph}, \mathrm{Ar}-\mathrm{H}^{2}, \mathrm{Ar}-\mathrm{H}^{6^{\prime}}\right), 7.25-7.38(\mathrm{~m}, 3 \mathrm{H}, \mathrm{Ph}), 7.83(\mathrm{~d}, J=9.0 \mathrm{~Hz}$, $\left.2 \mathrm{H}, \mathrm{Ar}-\mathrm{H}^{3^{\prime}}, \mathrm{Ar}-\mathrm{H}^{5^{\prime}}\right), 8.92$ (bs, $\left.2 \mathrm{H}, \mathrm{NH}_{2}\right), 9.16$ (bs, $\left.2 \mathrm{H}, \mathrm{NH}_{2}^{+}\right) ;{ }^{13} \mathrm{C} \mathrm{NMR}$ (101 MHz, DMSO-d 6 ): $\delta(\mathrm{ppm}) 13.4\left(\mathrm{CH}_{2}-\mathrm{CH}_{3}\right), 50.8\left(\mathrm{Ph}-\mathrm{CH}_{2}\right), 61.3$ $\left.\left(\mathrm{CH}_{2}-\mathrm{CH}_{3}\right), 64.4(\mathrm{C}-3), 66.7\left(\mathrm{CH}_{2} \mathrm{O}\right), 71.3 \overline{(\mathrm{C}}-2\right), 114.8\left(\overline{\mathrm{C}-2^{\prime}}, \mathrm{C}-6^{\prime}\right)$, 116.2 (C-7), 117.4 (C-5), 120.1 (C-4'), 120.9 (C-8), 127.6 (C-4"), 128.0 $\left(\mathrm{C}-2^{\prime \prime}, \mathrm{C}-6^{\prime \prime}\right), 128.6\left(\mathrm{C}-3^{\prime \prime}, \mathrm{C}-5^{\prime \prime}\right), 130.2\left(\mathrm{C}-3^{\prime}, \mathrm{C}-5^{\prime}\right), 132.3(\mathrm{C}-6), 136.1$ $\left(\mathrm{C}-1^{\prime \prime}\right), 142.6,142.7$ (C-4a, C-8a), 161.5, 162.3, 162.4, 164.5 (CO-COO, $\left.\mathrm{CO}-\mathrm{COO}, \mathrm{C}-1^{\prime}, \mathrm{C}(=\mathrm{NH}) \mathrm{NH}_{2}\right), 117,1\left(\mathrm{CF}_{3}-\mathrm{COOH},{ }^{1} J_{C, F}=2 \overline{99}, 3 \mathrm{~Hz}\right)$, $158,7\left(\mathrm{CF}_{3}-\mathrm{COOH},{ }^{2} J_{\mathrm{C}, \mathrm{F}}=31,5 \mathrm{~Hz}\right) ; \mathrm{HRMS}(\mathrm{ESI}) \mathrm{m} / \mathrm{z}$ calcd for $\mathrm{C}_{27} \mathrm{H}_{28} \mathrm{~N}_{3} \mathrm{O}_{6}[\mathrm{M}+\mathrm{H}]^{+}$490.1978, found 490.1967; IR $\left(\mathrm{KBr}, v, \mathrm{~cm}^{-1}\right)$ : 3299, 3116, 1737, 1667, 1506, 1203, 844; HPLC: 99.0\%, $t_{\mathrm{r}} 12.5 \mathrm{~min}$; Anal. $\left(\mathrm{C}_{27} \mathrm{H}_{27} \mathrm{~N}_{3} \mathrm{O}_{6} \times \mathrm{CF}_{3} \mathrm{COOH}\right) \mathrm{C}, \mathrm{H}, \mathrm{N}$.

6.21. (S)-ethyl 2-(benzyl(2-((4-carbamimidoylphenoxy)methyl)-2,3dihydro-1,4-benzodioxin-6-yl)amino)-2-oxoacetate trifluoroacetate (10b)

Synthesized from 9b (480 mg, $1.02 \mathrm{mmol})$ according to the general procedure for synthesis of amidines 10a-d; white powder, yield $325 \mathrm{mg}(53 \%) ; \mathrm{mp} 190-193{ }^{\circ} \mathrm{C} ;[\alpha]_{\mathrm{D}}=-32.0(c=0.5 \mathrm{in} \mathrm{EtOH})$; ${ }^{1} \mathrm{H}$ NMR (400 MHz, DMSO-d 6 ): $\delta(\mathrm{ppm}) 0.93(\mathrm{t}, J=7.1 \mathrm{~Hz}, 3 \mathrm{H}$, $\left.\mathrm{CH}_{2} \mathrm{CH}_{3}\right), 4.02\left(\mathrm{q}, J=7.1 \mathrm{~Hz}, 2 \mathrm{H}, \mathrm{CH}_{2} \mathrm{CH}_{3}\right), 4.14(\mathrm{dd}, J=11.6,7.4 \mathrm{~Hz}$, $\left.1 \mathrm{H}, 3-\mathrm{CH}_{2}\right), 4.32\left(\mathrm{dd}, J=11.0,5.7 \mathrm{~Hz}, 1 \mathrm{H}, \mathrm{CH}_{2} \mathrm{O}\right), 4.39$ (dd, $J=11.0$, $3.6 \mathrm{~Hz}, 1 \mathrm{H}, \mathrm{CH}_{2} \mathrm{O}$ ), 4.46 (dd, $J=11.6,2.4 \mathrm{~Hz}, 1 \mathrm{H}, 3-\mathrm{CH}_{2}$ ), $4.57-4.66$ $(\mathrm{m}, 1 \mathrm{H}, 2-\mathrm{CH}), 4.91\left(\mathrm{~s}, 2 \mathrm{H}, \mathrm{NCH}_{2}\right), 6.63(\mathrm{dd}, J=8.6,2.7 \mathrm{~Hz}, 1 \mathrm{H}$, $\left.\mathrm{Ar}-\mathrm{H}^{7}\right), 6.79\left(\mathrm{~d}, J=2.7 \mathrm{~Hz}, 1 \mathrm{H}, \mathrm{Ar}-\mathrm{H}^{5}\right), 6.89(\mathrm{~d}, J=8.6 \mathrm{~Hz}, 1 \mathrm{H}, \mathrm{Ar}-$ $\left.\mathrm{H}^{8}\right), 7.16-7.25\left(\mathrm{~m}, 4 \mathrm{H}, \mathrm{Ph}, \mathrm{Ar}-\mathrm{H}^{2}, \mathrm{Ar}-\mathrm{H}^{6^{\prime}}\right), 7.27-7.37(\mathrm{~m}, 3 \mathrm{H}, \mathrm{Ph})$, $7.83\left(\mathrm{~d}, J=9.0 \mathrm{~Hz}, 2 \mathrm{H}, \mathrm{Ar}-\mathrm{H}^{3^{\prime}}, \mathrm{Ar}-\mathrm{H}^{5}\right), 8.92\left(\mathrm{bs}, 2 \mathrm{H}, \mathrm{NH}_{2}\right), 9.16$ (bs, $\left.2 \mathrm{H}, \mathrm{NH}_{2}^{+}\right) ;{ }^{13} \mathrm{C}$ NMR (101 MHz, DMSO-d 6 ): $\delta(\mathrm{ppm}) 13.4\left(\mathrm{CH}_{2}-\mathrm{CH}_{3}\right)$, $50.8\left(\mathrm{Ph}-\mathrm{CH}_{2}\right), 61.3\left(\mathrm{CH}_{2}-\mathrm{CH}_{3}\right), 64.4(\mathrm{C}-3), 66.7\left(\mathrm{CH}_{2} \mathrm{O}\right), 71.3(\mathrm{C}-2)$, 114.8 (C-2', C-6' $), 116.2$ (C-7), 117.4 (C-5), 120.1 (C-4'), 120.9 (C-8), $127.6\left(\mathrm{C}-4^{\prime \prime}\right), 128.0\left(\mathrm{C}-2^{\prime \prime}, \mathrm{C}-6^{\prime \prime}\right), 128.6\left(\mathrm{C}-3^{\prime \prime}, \mathrm{C}-5^{\prime \prime}\right), 130.2\left(\mathrm{C}-3^{\prime}, \mathrm{C}-5^{\prime}\right)$, 132.3 (C-6), 136.1 (C-1"), 142.6, 142.7 (C-4a, C-8a), 161.5, 162.3, 162.4, 164.5 (CO-COO, CO-COO, C-1', C $(=\mathrm{NH}) \mathrm{NH}_{2}$ ), 117.1 $\left(\mathrm{CF}_{3}-\mathrm{COOH},{ }^{1} J_{C, F}=299.2 \mathrm{~Hz}\right), 158.8\left(\mathrm{CF}_{3}-\mathrm{COOH},{ }^{2} J_{C, F}=31.5 \mathrm{~Hz}\right)$; HRMS (ESI) $m / z$ calcd for $\mathrm{C}_{27} \mathrm{H}_{28} \mathrm{~N}_{3} \mathrm{O}_{6}[\mathrm{M}+\mathrm{H}]^{+} 490.1978$, found 490.1963; IR (KBr, $v, \mathrm{~cm}^{-1}$ ): 3298, 3122, 1737, 1665, 1506, 1203, 843; HPLC: $100 \%, t_{\mathrm{r}} 12.4 \mathrm{~min}$; Anal. $\left(\mathrm{C}_{27} \mathrm{H}_{27} \mathrm{~N}_{3} \mathrm{O}_{6} \times \mathrm{CF}_{3} \mathrm{COOH} \times 1 / 9 \mathrm{H}_{2} \mathrm{O}\right)$ C, H, N.

6.22. (R)-ethyl 2-(benzyl(3-((4-carbamimidoylphenoxy)methyl)-2,3dihydro-1,4-benzodioxin-7-yl)amino)-2-oxoacetate triluoroacetate (10c)

Synthesized from 9c (480 mg, $1.02 \mathrm{mmol}$ ) according to the general procedure for synthesis of amidines $\mathbf{1 0 a}-\mathbf{d}$; white powder, yield $335 \mathrm{mg}(54 \%)$; $\mathrm{mp} 185-188^{\circ} \mathrm{C} ;[\alpha]_{\mathrm{D}}=+11.8(c=2.0$, DMSO); ${ }^{1} \mathrm{H}$ NMR (400 MHz, DMSO-d 6 ): $\delta(\mathrm{ppm}) 0.91(\mathrm{t}, J=7.0 \mathrm{~Hz}, 3 \mathrm{H}$, $\left.\mathrm{CH}_{2} \mathrm{CH}_{3}\right), 4.00\left(\mathrm{q}, J=7.0 \mathrm{~Hz}, 2 \mathrm{H}, \mathrm{CH}_{2} \mathrm{CH}_{3}\right), 4.15$ (dd, $J=11.6,7.2 \mathrm{~Hz}$, $\left.1 \mathrm{H}, 3-\mathrm{CH}_{2}\right), 4.31$ (dd, $\left.J=11.0,6.0 \mathrm{~Hz}, 1 \mathrm{H}, \mathrm{CH}_{2} \mathrm{O}\right), 4.39$ (dd, $J=11.0$, $3.4 \mathrm{~Hz}, 1 \mathrm{H}, \mathrm{CH}_{2} \mathrm{O}$ ), 4.46 (dd, $\left.J=11.6,2.2 \mathrm{~Hz}, 1 \mathrm{H}, 3-\mathrm{CH}_{2}\right), 4.58-4.64$ $(\mathrm{m}, 1 \mathrm{H}, 2-\mathrm{CH}), 4.90\left(\mathrm{~s}, 2 \mathrm{H}, \mathrm{NCH}_{2}\right), 6.63(\mathrm{dd}, J=8.7,2.5 \mathrm{~Hz}, 1 \mathrm{H}, \mathrm{Ar}-$ $\left.\mathrm{H}^{6}\right), 6.80\left(\mathrm{~d}, J=2.5 \mathrm{~Hz}, 1 \mathrm{H}, \mathrm{Ar}-\mathrm{H}^{8}\right), 6.89\left(\mathrm{~d}, J=8.7 \mathrm{~Hz}, 1 \mathrm{H}, \mathrm{Ar}-\mathrm{H}^{5}\right)$, 7.15-7.38 (m, 7H, Ph, Ar- $\left.\mathrm{H}^{2}, \mathrm{Ar}-\mathrm{H}^{6^{\prime}}\right), 7.83(\mathrm{~d}, J=8.9 \mathrm{~Hz}, 2 \mathrm{H}, \mathrm{Ar}-$ $\mathrm{H}^{3^{\prime}}, \mathrm{Ar}-\mathrm{H}^{5^{\prime}}$ ), 8.91 (bs, $2 \mathrm{H}, \mathrm{NH}_{2}$ ), 9.17 (bs, $2 \mathrm{H}, \mathrm{NH}_{2}^{+}$); ${ }^{13} \mathrm{C} \mathrm{NMR}$
(101 MHZ, DMSO-d $\left.\mathrm{d}_{6}\right): \delta(\mathrm{ppm}) 13.3\left(\mathrm{CH}_{2}-\mathrm{CH}_{3}\right), 50.8\left(\mathrm{Ph}-\mathrm{CH}_{2}\right), 61.3$ $\left(\mathrm{CH}_{2}-\mathrm{CH}_{3}\right), 64.4(\mathrm{C}-3), 66.7\left(\mathrm{CH}_{2} \mathrm{O}\right), 71.3(\mathrm{C}-2), 114.8\left(\mathrm{C}-2^{\prime}, \mathrm{C}-6^{\prime}\right)$, 116.2 (C-6), 117.3 (C-5), 120.1 (C-4'), 120.8 (C-8), 127.5 (C-4"), 127.9 (C-2", C-6 $\left.6^{\prime \prime}\right), 128.6\left(C-3^{\prime \prime}, C-5^{\prime \prime}\right), 130.2\left(C-3^{\prime}, C-5^{\prime}\right), 132.5(C-7), 136.1$ (C-1") $142.5,142.8$ (C-4a, C-8a), 161.5, 162.3, 162.4, 164.5 (CO-COO, $\left.\mathrm{CO}-\mathrm{COO}, \mathrm{C}-1^{\prime}, \mathrm{C}(=\mathrm{NH}) \mathrm{NH}_{2}\right), 117.1\left(\underline{\mathrm{CF}}_{3}-\mathrm{COOH},{ }^{1} J_{\mathrm{C}, \mathrm{F}}=299.2 \mathrm{~Hz}\right)$, $158.8\left(\mathrm{CF}_{3}-\mathrm{COOH},{ }^{2} \mathrm{~J}_{\mathrm{C}, \mathrm{F}}=31.5 \mathrm{~Hz}\right)$; HRMS (ESI) $\mathrm{m} / \mathrm{z}$ calcd for $\mathrm{C}_{27} \mathrm{H}_{28} \mathrm{~N}_{3} \mathrm{O}_{6} \overline{[\mathrm{M}+\mathrm{H}]^{+}}$490.1978, found 490.1996; IR $\left(\mathrm{KBr}, v, \mathrm{~cm}^{-1}\right)$ : 3345, 3109, 1742, 1670, 1500, 1197, 843; HPLC: 98.4\%, $t_{\mathrm{r}} 12.7 \mathrm{~min}$; Anal. $\left(\mathrm{C}_{27} \mathrm{H}_{27} \mathrm{~N}_{3} \mathrm{O}_{6} \times \mathrm{CF}_{3} \mathrm{COOH}\right) \mathrm{C}, \mathrm{H}, \mathrm{N}$.

6.23. (S)-ethyl 2-(benzyl(3-((4-carbamimidoylphenoxy)methyl)2,3-dihydro-1,4-benzodioxin-7-yl)amino)-2-oxoacetate (10d)

Synthesized from 9d (480 mg, $1.02 \mathrm{mmol}$ ) according to the general procedure for synthesis of amidines 10a-d; white powder, yield $345 \mathrm{mg}(56 \%) ; \mathrm{mp} 188-191{ }^{\circ} \mathrm{C} ;[\alpha]_{\mathrm{D}}=-12.8(c=2.0$, DMSO); ${ }^{1} \mathrm{H}$ NMR (400 MHz, DMSO-d 6 ): $\delta(\mathrm{ppm}) 0.91(\mathrm{t}, J=7.1 \mathrm{~Hz}$, $\left.3 \mathrm{H}, \mathrm{CH}_{2} \mathrm{CH}_{3}\right), 4.00$ (q, $\left.J=7.1 \mathrm{~Hz}, 2 \mathrm{H}, \mathrm{CH}_{2} \mathrm{CH}_{3}\right), 4.15$ (dd, $J=11.6$, $\left.7.3 \mathrm{~Hz}, 1 \mathrm{H}, 3-\mathrm{CH}_{2}\right), 4.31$ (dd, $J=11.0,5.9 \mathrm{~Hz}, 1 \mathrm{H}, \mathrm{CH}_{2} \mathrm{O}$ ), 4.39 (dd, $\left.J=11.0,3.5 \mathrm{~Hz}, 1 \mathrm{H}, \mathrm{CH}_{2} \mathrm{O}\right), 4.46\left(\mathrm{dd}, J=11.6,2.2 \mathrm{~Hz}, 1 \mathrm{H}, 3-\mathrm{CH}_{2}\right)$, 4.53-4.68 (m, $1 \mathrm{H}, 2-\mathrm{CH}), 4.90\left(\mathrm{~s}, 2 \mathrm{H}, \mathrm{NCH}_{2}\right), 6.63$ (dd, $J=8.6$, $\left.2.5 \mathrm{~Hz}, 1 \mathrm{H}, \mathrm{Ar}-\mathrm{H}^{6}\right), 6.80\left(\mathrm{~d}, J=2.5 \mathrm{~Hz}, 1 \mathrm{H}, \mathrm{Ar}-\mathrm{H}^{8}\right), 6.89(\mathrm{~d}$, $\left.J=8.6 \mathrm{~Hz}, 1 \mathrm{H}, \mathrm{Ar}-\mathrm{H}^{5}\right), 7.17-7.24\left(\mathrm{~m}, 4 \mathrm{H}, \mathrm{Ph}, \mathrm{Ar}-\mathrm{H}^{2}, \mathrm{Ar}-\mathrm{H}^{6}\right), 7.26-$ 7.37 (m, 3H, Ph), 7.83 (d, $\left.J=8.9 \mathrm{~Hz}, 2 \mathrm{H}, \mathrm{Ar}-\mathrm{H}^{3}, \mathrm{Ar}-\mathrm{H}^{5}\right), 8.93$ (bs, $2 \mathrm{H}, \mathrm{NH}_{2}$ ), 9.17 (bs, $2 \mathrm{H}, \mathrm{NH}_{2}^{+}$); ${ }^{13} \mathrm{C}$ NMR (101 MHz, DMSO-d 6 ): $\delta(\mathrm{ppm}) 13.3\left(\mathrm{CH}_{2}-\mathrm{CH}_{3}\right), 50.8\left(\mathrm{Ph}-\mathrm{CH}_{2}\right), 61.3\left(\mathrm{CH}_{2}-\mathrm{CH}_{3}\right), 64.4(\mathrm{C}-$ 3), $66.7\left(\mathrm{CH}_{2} \mathrm{O}\right), 71.3(\mathrm{C}-2), 114.8\left(\mathrm{C}-2^{\prime}, \mathrm{C}-6^{\prime}\right), 116.2(\mathrm{C}-6), 117.3(\mathrm{C}-$ 5), $120.1\left(\mathrm{C}-4^{\prime}\right), 120.8$ (C-8), $127.5\left(\mathrm{C}-4^{\prime \prime}\right), 127.9$ (C-2", $\left.\mathrm{C}-6^{\prime \prime}\right), 128.6$ (C-3", C-5"), $130.2\left(\mathrm{C}-3^{\prime}, \mathrm{C}^{\prime \prime} 5^{\prime}\right), 132.5$ (C-7), 136.1 (C-1"), 142.5, 142.8 (C-4a, C-8a), 161.5, 162.3, 162.4, 164.5 (CO-COO, CO-COO, C$\left.1^{\prime}, \mathrm{C}(=\mathrm{NH}) \mathrm{NH}_{2}\right)$; HRMS (ESI) $m / z$ calcd for $\overline{\mathrm{C}_{27}} \mathrm{H}_{28} \mathrm{~N}_{3} \mathrm{O}_{6}[\overline{\mathrm{M}+\mathrm{H}}]^{+}$ 490.1978, found 490.1987; IR $\left(\mathrm{KBr}, v, \mathrm{~cm}^{-1}\right)$ : 3342, 3110, 1742, 1670, 1499, 1196, 844; HPLC: 98.4\%, $t_{\mathrm{r}} 12.7 \mathrm{~min}$; Anal. $\left(\mathrm{C}_{27} \mathrm{H}_{27} \mathrm{~N}_{3} \mathrm{O}_{6} \times \mathrm{CF}_{3} \mathrm{COOH}\right) \mathrm{C}, \mathrm{H}, \mathrm{N}$.

6.24. (R)-2-(benzyl(2-((4-carbamimidoylphenoxy)methyl)-2,3dihydro-1,4-benzodioxin-6-yl)amino)-2-oxoacetic acid (11a). General procedure for synthesis of compounds 11a-d

To a solution of 10a (150 mg, $0.31 \mathrm{mmol})$ in a mixture of tetrahydrofuran $(3 \mathrm{~mL})$ and methanol $(1 \mathrm{~mL}), 1 \mathrm{M} \mathrm{LiOH}(1.50 \mathrm{~mL}$, $1.50 \mathrm{mmol}$ ) was added and the reaction mixture stirred at room temperature for $1 \mathrm{~h}$. The solvents was evaporated in vacuum and the resulting aqueous solution neutralized with $0.1 \%$ trifluoroacetic acid until the product started to precipitate $(\mathrm{pH}=2)$. The product was filtered off and dried to obtain $79 \mathrm{mg}(68 \%)$ of 11a as a white powder; $\mathrm{mp} 290-293{ }^{\circ} \mathrm{C} ;[\alpha]_{\mathrm{D}}=+59.6(c=2.0$, DMSO); ${ }^{1} \mathrm{H}$ NMR (400 MHz, DMSO-d 6 ): $\delta(\mathrm{ppm}) 4.14(\mathrm{dd}, J=11.6,7.6 \mathrm{~Hz}$, $\left.1 \mathrm{H}, 3-\mathrm{CH}_{2}\right), 4.33\left(\mathrm{dd}, J=11.0,5.6 \mathrm{~Hz}, 1 \mathrm{H}, \mathrm{CH}_{2} \mathrm{O}\right), 4.40$ (dd, $J=11.0$, $3.7 \mathrm{~Hz}, 1 \mathrm{H}, \mathrm{CH}_{2} \mathrm{O}$ ), 4.46 (dd, $\left.J=11.6,2.3 \mathrm{~Hz}, 1 \mathrm{H}, 3-\mathrm{CH}_{2}\right), 4.57-4.66$ $(\mathrm{m}, 1 \mathrm{H}, 2-\mathrm{CH}), 4.88\left(\mathrm{~s}, 2 \mathrm{H}, \mathrm{NCH}_{2}\right), 6.67$ (dd, $J=8.6,2.5 \mathrm{~Hz}, 1 \mathrm{H}, \mathrm{Ar}-$ $\left.\mathrm{H}^{7}\right), 6.80\left(\mathrm{~d}, J=2.5 \mathrm{~Hz}, 1 \mathrm{H}, \mathrm{Ar}-\mathrm{H}^{5}\right), 6.89(\mathrm{~d}, J=8.6 \mathrm{~Hz}, 1 \mathrm{H}, \mathrm{Ar}-$ $\left.\mathrm{H}^{8}\right), 7.18-7.24\left(\mathrm{~m}, 4 \mathrm{H}, \mathrm{Ph}, \mathrm{Ar}-\mathrm{H}^{2}, \mathrm{Ar}-\mathrm{H}^{6^{6}}\right), 7.27-7.35(\mathrm{~m}, 3 \mathrm{H}$, $\mathrm{Ph}), 7.83\left(\mathrm{~d}, J=8.9 \mathrm{~Hz}, 2 \mathrm{H}, \mathrm{Ar}-\mathrm{H}^{3^{\prime}}, \mathrm{Ar}-\mathrm{H}^{5^{\prime}}\right), 9.04$ (bs, $\left.2 \mathrm{H}, \mathrm{NH}_{2}\right)$, 9.17 (bs, $1 \mathrm{H}, \mathrm{NH}) ;{ }^{13} \mathrm{C}$ NMR (101 MHz, DMSO-d 6 ): $\delta$ (ppm) 49.6 $\left(\mathrm{Ph}-\mathrm{CH}_{2}\right), 64.4(\mathrm{C}-3), 66.7\left(\mathrm{CH}_{2} \mathrm{O}\right), 71.0(\mathrm{C}-2), 114.7\left(\mathrm{C}-2^{\prime}, \mathrm{C}-6^{\prime}\right)$, 115.9 (C-7), 116.6 (C-5), 120.2 (C-4'), 120.6 (C-8), $127.0\left(\mathrm{C}-4^{\prime \prime}\right)$, $127.6\left(\mathrm{C}-2^{\prime \prime}, \mathrm{C}-6^{\prime \prime}\right), 128.3\left(\mathrm{C}-3^{\prime \prime}, \mathrm{C}-5^{\prime \prime}\right), 129.8\left(\mathrm{C}-3^{\prime}, \mathrm{C}-5^{\prime}\right), 132.3(\mathrm{C}-$ 6), 137.7 (C-1" ), 141.4, 142.0 (C-4a, C-8a), 162.0, 163.2, 164.0, 164.6 (CO-COO, $\left.\mathrm{CO}-\mathrm{COO}, \mathrm{C}-1^{\prime}, \mathrm{C}(=\mathrm{NH}) \mathrm{NH}_{2}\right)$; HRMS (ESI) $\mathrm{m} / \mathrm{z}$ calcd for $\mathrm{C}_{25} \mathrm{H}_{24} \mathrm{~N}_{3} \mathrm{O}_{6}[\mathrm{M}+\mathrm{H}]^{+} 462.1665$, found 462.1674; IR (KBr, $v$, $\left.\mathrm{cm}^{-1}\right)$ : 3368, 1609, 1503, 1255, 844; HPLC: 96.1\%, $t_{\mathrm{r}} 9.5 \mathrm{~min}$; Anal. $\left(\mathrm{C}_{25} \mathrm{H}_{23} \mathrm{~N}_{3} \mathrm{O}_{6} \times 1 / 3 \mathrm{CF}_{3} \mathrm{COOH}\right) \mathrm{C}, \mathrm{H}, \mathrm{N}$. 
6.25. (S)-2-(benzyl(2-((4-carbamimidoylphenoxy)methyl)-2,3dihydro-1,4-benzodioxin-6-yl)amino)-2-oxoacetic acid (11b)

Synthesized from 10b (150 $\mathrm{mg}, 0.25 \mathrm{mmol}$ ) according to the general procedure for synthesis of compounds 11a-d; white powder, yield $69 \mathrm{mg}(60 \%) ; \mathrm{mp} 294-297{ }^{\circ} \mathrm{C} ;[\alpha]_{\mathrm{D}}=-56.8(c=2.0$ in DMSO); ${ }^{1} \mathrm{H}$ NMR (400 MHz, DMSO-d 6 ): $\delta(\mathrm{ppm}) 3.91(\mathrm{dd}, J=11.2$, $7.1 \mathrm{~Hz}, 1 \mathrm{H}, 3-\mathrm{CH}_{2}$ ), 3.97 (dd, $J=10.1,5.9 \mathrm{~Hz}, 1 \mathrm{H}, \mathrm{CH}_{2} \mathrm{O}$ ), 4.08 (dd, $\left.J=10.1,5.5 \mathrm{~Hz}, 1 \mathrm{H}, \mathrm{CH}_{2} \mathrm{O}\right), 4.31$ (dd, $J=11.2,1.4 \mathrm{~Hz}, 1 \mathrm{H}, 3-\mathrm{CH}_{2}$ ), $4.36-4.44(\mathrm{~m}, 1 \mathrm{H}, 2-\mathrm{CH}), 4.83$ (d, $\left.J=15.3 \mathrm{~Hz}, 1 \mathrm{H}, \mathrm{NCH}_{2}\right), 4.89$ (d, $\left.J=15.3 \mathrm{~Hz}, 1 \mathrm{H}, \mathrm{NCH}_{2}\right), 6.73-6.85\left(\mathrm{~m}, 3 \mathrm{H}, \mathrm{Ar}-\mathrm{H}^{8}, \mathrm{Ar}-\mathrm{H}^{7}, \mathrm{Ar}-\mathrm{H}^{5}\right)$, $7.03\left(\mathrm{~d}, J=8.8 \mathrm{~Hz}, 2 \mathrm{H}, \mathrm{Ar}-\mathrm{H}^{2}, \mathrm{Ar}-\mathrm{H}^{6^{\prime}}\right), 7.17-7.24(\mathrm{~m}, 3 \mathrm{H}, \mathrm{Ph})$, $7.27-7.33(\mathrm{~m}, 2 \mathrm{H}, \mathrm{Ph}), 7.82\left(\mathrm{~d}, J=8.8 \mathrm{~Hz}, 2 \mathrm{H}, \mathrm{Ar}-\mathrm{H}^{3^{\prime}}, \mathrm{Ar}-\mathrm{H}^{5^{\prime}}\right), 9.01$ (bs, $2 \mathrm{H}, \mathrm{NH}_{2}$ ), 9.96 (bs, $\left.1 \mathrm{H}, \mathrm{NH}\right) ;{ }^{13} \mathrm{C}$ NMR (101 MHz, DMSO-d 6 ): $\delta(\mathrm{ppm}) 50.6\left(\mathrm{Ph}-\mathrm{CH}_{2}\right), 64.4(\mathrm{C}-3), 66.8\left(\mathrm{CH}_{2} \mathrm{O}\right), 71.3(2-\mathrm{C}), 114.9(\mathrm{C}-$ 2', C-6'), 116.1 (C-7), 117.3 (C-5), 120.1 (C-4'), 120.9 (C-8), 127.4 (C$\left.4^{\prime \prime}\right), 127.8\left(\mathrm{C}-2^{\prime \prime}, \mathrm{C}-6^{\prime \prime}\right), 128.5\left(\mathrm{C}-3^{\prime \prime}, \mathrm{C}-5^{\prime \prime}\right), 130.2\left(\mathrm{C}-3^{\prime}, \mathrm{C}-5^{\prime}\right), 132.8$ (C6), 136.3 (C-1" ), 142.5, 142.6 (C-4a, C-8a), 162.3, 163.0, 164.1, 164.5 (COCOO, CO-COO, C-1', C $=\mathrm{NH}) \mathrm{NH}_{2}$ ); HRMS (ESI) $\mathrm{m} / z$ calcd for $\overline{\mathrm{C}}_{25} \mathrm{H}_{24} \mathrm{~N}_{3} \mathrm{O}_{6}[\overline{\mathrm{M}}+\mathrm{H}]^{+}$462.1665, found 462.1669; IR $\left(\mathrm{KBr}, v, \mathrm{~cm}^{-1}\right)$ : 3311, 1610, 1500, 1267, 840; HPLC: 96.6\%, $t_{\mathrm{r}} 9.4 \mathrm{~min}$; Anal. $\left(\mathrm{C}_{25} \mathrm{H}_{23} \mathrm{~N}_{3} \mathrm{O}_{6} \times 1 / 15 \mathrm{CF}_{3} \mathrm{COOH}\right) \mathrm{C}, \mathrm{H}, \mathrm{N}$.

\subsection{6. (R)-2-(benzyl(3-((4-carbamimidoylphenoxy)methyl)-2,3-} dihydro-1,4-benzodioxin-7-yl)amino)-2-oxoacetic acid (11c)

Synthesized from 10c (150 mg, $0.25 \mathrm{mmol}$ ) according to the general procedure for synthesis of compounds 11a-d; white powder, yield $76 \mathrm{mg}(66 \%) ; \mathrm{mp} 291-294^{\circ} \mathrm{C} ;[\alpha]_{\mathrm{D}}=+16.8(c=2.0$ in DMSO); ${ }^{1} \mathrm{H}$ NMR (400 MHz, DMSO-d $\left.{ }_{6}\right): \delta(\mathrm{ppm}) 3.86-3.99(\mathrm{~m}, 2 \mathrm{H}$, $3-\mathrm{CH}_{2}, \mathrm{CH}_{2} \mathrm{O}$ ), 4.08 (dd, $J=10.1,5.3 \mathrm{~Hz}, 1 \mathrm{H}, \mathrm{CH}_{2} \mathrm{O}$ ), 4.30 (dd, $J=11.3$, $\left.1.8 \mathrm{~Hz}, 1 \mathrm{H}, 3-\mathrm{CH}_{2}\right), 4.35-4.45(\mathrm{~m}, 1 \mathrm{H}, 2-\mathrm{CH}), 4.82(\mathrm{~d}, J=15.3 \mathrm{~Hz}, 1 \mathrm{H}$, $\left.\mathrm{NCH}_{2}\right), 4.90\left(\mathrm{~d}, J=15.3 \mathrm{~Hz}, 1 \mathrm{H}, \mathrm{NCH}_{2}\right), 6.74-6.79\left(\mathrm{~m}, 2 \mathrm{H}, \mathrm{Ar}-\mathrm{H}^{8}\right.$, $\left.\mathrm{Ar}-\mathrm{H}^{6}\right), 6.81\left(\mathrm{~d}, J=8.6 \mathrm{~Hz}, 1 \mathrm{H}, \mathrm{Ar}-\mathrm{H}^{5}\right), 7.01(\mathrm{~d}, J=8.8 \mathrm{~Hz}, 2 \mathrm{H}$, $\left.\mathrm{Ar}-\mathrm{H}^{2}, \mathrm{Ar}-\mathrm{H}^{6^{\prime}}\right), 7.16-7.26(\mathrm{~m}, 3 \mathrm{H}, \mathrm{Ph}), 7.27-7.33(\mathrm{~m}, 2 \mathrm{H}, \mathrm{Ph}), 7.83$ $\left(\mathrm{d}, J=8.8 \mathrm{~Hz}, 2 \mathrm{H}, \mathrm{Ar}-\mathrm{H}^{3}, \mathrm{Ar}-\mathrm{H}^{5^{\prime}}\right), 9.06$ (bs, $\left.2 \mathrm{H}, \mathrm{NH}_{2}\right), 9.80$ (bs, $1 \mathrm{H}$, $\mathrm{NH}) ;{ }^{13} \mathrm{C}$ NMR (101 MHz, DMSO-d 6 ): $\delta(\mathrm{ppm}) 49.4\left(\mathrm{Ph}-\underline{\mathrm{CH}}_{2}\right), 64.5$ (C-3), $65.9\left(\mathrm{CH}_{2} \mathrm{O}\right), 71.0$ (C-2), $114.7\left(\mathrm{C}-2^{\prime}, \mathrm{C}^{\prime} 6^{\prime}\right), 115.2$ (C-8), 116.9 (C-6), $118.9\left(\mathrm{C}-4^{\prime}\right), 120.1(\mathrm{C}-5), 126.9\left(\mathrm{C}-4^{\prime \prime}\right), 127.3\left(\mathrm{C}-2^{\prime \prime}, \mathrm{C}-6^{\prime \prime}\right), 128.3$ (C-3", C-5"), $129.8\left(C-3^{\prime}, C-5^{\prime}\right), 135.5$ (C-7), 137.8 (C-1"1 ), 141.1, 141.6 (C-4a, C-8a), 161.9, 163.2, 164.0, 164.2 (CO-COO, CO-COO, C-1', C $=$ $\mathrm{NH}) \mathrm{NH}_{2}$ ); HRMS (ESI) $m / z$ calcd for $\mathrm{C}_{25} \overline{\mathrm{H}}_{24} \mathrm{~N}_{3} \mathrm{O}_{6}[\mathrm{M}+\overline{\mathrm{H}}]^{+} 462.1665$, found 462.1668; IR $\left(\mathrm{KBr}, v, \mathrm{~cm}^{-1}\right)$ : 3385, 1609, 1508, 1259, 845; HPLC: $94.0 \%, t_{\mathrm{r}} 9.7 \mathrm{~min}$; Anal. $\left(\mathrm{C}_{25} \mathrm{H}_{23} \mathrm{~N}_{3} \mathrm{O}_{6} \times 2 / 5 \mathrm{CF}_{3} \mathrm{COOH} \times 2 /\right.$ $\left.5 \mathrm{H}_{2} \mathrm{O}\right) \mathrm{C}, \mathrm{H}, \mathrm{N}$.

\subsection{7. (S)-2-(benzyl(3-((4-carbamimidoylphenoxy)methyl)-2,3-} dihydro-1,4-benzodioxin-7-yl)amino)-2-oxoacetic acid (11d)

Synthesized from 10d (150 $\mathrm{mg}, 0.25 \mathrm{mmol}$ ) according to the general procedure for synthesis of compounds 11a-d; yield $72 \mathrm{mg}(62 \%) ; \mathrm{mp} 290-293{ }^{\circ} \mathrm{C} ;[\alpha]_{\mathrm{D}}=-17.5$ (c=2.0 in DMSO); ${ }^{1} \mathrm{H}$ NMR (400 MHz, DMSO-d 6 ): $\delta(\mathrm{ppm}) 4.13(\mathrm{dd}, J=11.6,7.9 \mathrm{~Hz}, 1 \mathrm{H}$, $3-\mathrm{CH}_{2}$ ), 4.34 (dd, $J=10.9,5.6 \mathrm{~Hz}, 1 \mathrm{H}, \mathrm{CH}_{2} \mathrm{O}$ ), 4.40 (dd, $J=10.9$, $3.6 \mathrm{~Hz}, 1 \mathrm{H}, \mathrm{CH}_{2} \mathrm{O}$ ), 4.48 (dd, $J=11.6,2.2 \mathrm{~Hz}, 1 \mathrm{H}, 3-\mathrm{CH}_{2}$ ), 4.55$4.65(\mathrm{~m}, 1 \mathrm{H}, 2-\mathrm{CH}), 4.88\left(\mathrm{~s}, 2 \mathrm{H}, \mathrm{NCH}_{2}\right), 6.68$ (dd, $J=8.6,2.5 \mathrm{~Hz}$, $\left.1 \mathrm{H}, \mathrm{Ar}-\mathrm{H}^{6}\right), 6.80\left(\mathrm{~d}, J=2.5 \mathrm{~Hz}, 1 \mathrm{H}, \mathrm{Ar}-\mathrm{H}^{8}\right), 6.89(\mathrm{~d}, J=8.6 \mathrm{~Hz}$, $\left.1 \mathrm{H}, \mathrm{Ar}-\mathrm{H}^{5}\right), 7.18-7.37\left(\mathrm{~m}, 7 \mathrm{H}, \mathrm{Ph}, \mathrm{Ar}-\mathrm{H}^{2}, \mathrm{Ar}-\mathrm{H}^{6}\right), 7.83(\mathrm{~d}$, $\left.J=8.9 \mathrm{~Hz}, 2 \mathrm{H}, \mathrm{Ar}-\mathrm{H}^{3}, \mathrm{Ar}-\mathrm{H}^{5^{\prime}}\right), 8.91\left(\mathrm{~s}, 2 \mathrm{H}, \mathrm{NH}_{2}\right), 9.17$ (s, 1H, NH); ${ }^{13} \mathrm{C}$ NMR (101 MHz, DMSO-d 6$): \delta(\mathrm{ppm}) 50.6\left(\mathrm{Ph}-\mathrm{CH}_{2}\right), 64.4(\mathrm{C}-$ 3), $66.8\left(\mathrm{CH}_{2} \mathrm{O}\right), 71.4(\mathrm{C}-2), 114.9\left(\mathrm{C}-2^{\prime}, \mathrm{C}-6^{\prime}\right), 116.1(\mathrm{C}-8), 117.3(\mathrm{C}-$ 6), $120.1\left(\mathrm{C}-4^{\prime}\right), 120.7$ (C-5), $127.4\left(\mathrm{C}-4^{\prime \prime}\right), 127.8\left(\mathrm{C}-2^{\prime \prime}, \mathrm{C}-6^{\prime \prime}\right), 128.5$ $\left(\mathrm{C}-3^{\prime \prime}, \mathrm{C}-5^{\prime \prime}\right), 130.2\left(\mathrm{C}-3^{\prime}, \mathrm{C}-5^{\prime}\right), 133.0(\mathrm{C}-7), 136.3\left(\mathrm{C}-1^{\prime \prime}\right), 142.5$, 142.6(C-4a, C-8a), 162.3, 163.1, 164.2, 164.5 (CO-COO, CO-COO, $\left.\mathrm{C}-1^{\prime}, \quad \mathrm{C}(=\mathrm{NH}) \mathrm{NH}_{2}\right) ;$ HRMS (ESI) $\mathrm{m} / \mathrm{z}$ calcd for $\mathrm{C}_{25} \mathrm{H}_{24} \overline{\mathrm{N}_{3}} \mathrm{O}_{6}$
$[\mathrm{M}+\mathrm{H}]^{+}$462.1665, found 462.1684; IR $\left(\mathrm{KBr}, v, \mathrm{~cm}^{-1}\right)$ : 3309, 1609, 1492, 1262, 839; HPLC: 96.2\%, $t_{\mathrm{r}} 9.7 \mathrm{~min}$; Anal. $\left(\mathrm{C}_{25} \mathrm{H}_{23} \mathrm{~N}_{3} \mathrm{O}_{6} \times 1 / 11 \mathrm{CF}_{3} \mathrm{COOH}\right) \mathrm{C}, \mathrm{H}, \mathrm{N}$.

\subsection{Docking studies}

The binding modes of the ligands to both targets were studied by Autodock 4.0 [53]. The energetically most favorable conformation was found for each stereoisomer with HyperChem, using the semiempirical method MNDO. All amide bonds had trans configuration and were marked as non-rotatable. Compounds were protonated on the basic center (amidino, or amino group) and were assigned with a negative charge on the acidic center (carboxylic group). The crystal structures of thrombin (PDB entry code: 1KTS) [48] and GP IIb/IIIa (PDB entry code: 2VDM) [49] were extracted from the Brookhaven Protein Database. The PDB crystal structures were prepared for docking by removing water molecules and ligands. In the case of $\mathbf{2 V D M}$, the magnesium ion in the active site was retained and manually assigned a charge of +2 and solvation parameters. The ligands were docked into a restricted box centered in the active site $(22 \AA \times 22 \AA \times 22 \AA)$. For the global search using the LGA (Lamarckian genetic algorithm), the size of the initial random population was 250 individuals, the maximal number of energy evaluations $1.25 \times 10^{6}$, the maximal number of generations 500 , the number of top individuals that survived into the next generation (the elitism) 1, the probability that a gene would undergo a random change 0.02 , and the crossover probability 0.80 . The average of the worst energy was calculated over a window of 10 generations. For a purely local search, the pseudo Solis and Wets method was used, whereas the Solis and Wets method was used for the LGA part of the local search. The parameters used for local search in both cases were a maximum of 1000 iterations per local search, the probability of performing a local search on an individual was 1.0, the maximal number of consecutive successes or failures before doubling or halving the step size of the local search was 4 , and the lower bound on the step size, 0.01, was the termination criterion for the local search. A total of 250 dockings were performed, and ligands with RMSD less than 1 were joined in clusters. The ligand with the lowest docked energy was chosen for interpreting the docking results.

\subsection{Biochemical evaluation}

\subsubsection{Enzyme assay for inhibition of serine proteases}

The enzymic amidolytic method for determining inhibition of thrombin, factor Xa and trypsin was based on the spectrophotometric determination of absorbance of the product formed after amide bond cleavage of a chromogenic substrate in the presence of the enzyme. $K_{\mathrm{i}}$, which is a quantitative measure of inhibitor potency, was determined from the kinetics of substrate hydrolysis with and without the addition of the inhibitor. Measurements (spectrophotometer, BioTek Synergy H4) were performed in 96-well microtiter plates with a final volume of $200 \mu \mathrm{L}$. Thrombin was tested in a final concentration of $0.5 \mathrm{NIH} \mathrm{E} / \mathrm{mL}$ with the substrate S-2238 (Chromogenix) at 20 and $40 \mu \mathrm{M}$ final concentration, and factor Xa at the final concentration of $1 \mathrm{mBAEE} \mathrm{E} / \mathrm{mL}$ with the substrate $\mathrm{S}-2222$ (Chromogenix) at 100 and $200 \mu \mathrm{M}$ final concentrations.

Trypsin was assayed at a final concentration of $0.5 \mathrm{nkat} / \mathrm{mL}$ using the substrate S-2222 (Chromogenix) at 50 and $100 \mu \mathrm{M}$ final concentrations. Inhibitors were dissolved in DMSO (concentration of stock solutions, $10 \mathrm{mmol} / \mathrm{L}$ ) and diluted with distilled water to concentrations from 0.5 to $100 \mu \mathrm{M}$. Reaction rates were measured in the presence and the absence of the inhibitor. Then $50 \mu \mathrm{M}$ HBSA buffer, the $50 \mu \mathrm{M}$ solution of each inhibitor concentration (or of HBSA buffer in case of measurement without inhibitor), and 
$50 \mu \mathrm{M}$ of enzyme solution were pipetted into the microtiter wells. The plate was incubated for $15 \mathrm{~min}$ at $25{ }^{\circ} \mathrm{C}$ and $50 \mu \mathrm{L}$ of chromogenic substrate then added. Absorbance at $405 \mathrm{~nm}$ was measured every $10 \mathrm{~s}$ at $25{ }^{\circ} \mathrm{C}$. Measurements were carried out in triplicate with three concentrations of the inhibitor and two concentrations of the substrate. For every combination of concentrations, $K_{\mathrm{i}}$ was calculated from the change of absorbance in the initial, linear part of the curve according to the method of Cheng and Prusoff [54] and the final result was given as their average value. Dabigatran (thrombin, $K_{\mathrm{i}}=6.3 \pm 1.1 \mathrm{nM}$ ) was used as control.

\subsubsection{Inhibition of in vitro binding of fibrinogen to isolated GPIIb/ IIIa and GPV/IIIa receptors}

Binding affinities to GPIIb/IIIa and GPV/IIIa receptor were measured by a solid-phase competitive displacement assay. Human fibrinogen (100 mg) was dissolved in aqueous $\mathrm{NaCl}(0.3 \mathrm{M}, 5 \mathrm{~mL})$ at $30{ }^{\circ} \mathrm{C}$ and then it was diluted with $0.1 \mathrm{M} \mathrm{NaHCO}_{3}$ in water to a final concentration of $1 \mathrm{mg} / \mathrm{mL}$. Biotin $N$-hydroxysuccinimide ester $(2 \mathrm{mg})$ was dissolved in DMF (2 mL) and added to $6 \mathrm{~mL}$ of fibrinogen solution. The reaction mixture was incubated for $90 \mathrm{~min}$ at $30^{\circ} \mathrm{C}$ and dialyzed for $3 \mathrm{~h}$ at room temperature against buffer 1 ( $3 \mathrm{~L}$, $20 \mathrm{mM}$ Tris, $150 \mathrm{mM} \mathrm{NaCl}, \mathrm{pH}$ 7.4). After dialysis, the solution was centrifuged for $5 \mathrm{~min}$ at $5400 \mathrm{rpm}$ and Tween-20 (0.005\%) added to give the stock solution. Human integrin ( $10 \mu \mathrm{L}$ of GPIIb/IIIa receptor solution (Calbiochem), $1 \mu \mathrm{L}$ of GPV/IIla receptor solution (Calbiochem)) was diluted in $10.2 \mathrm{~mL}$ of buffer 2 (50 mM Tris, $150 \mathrm{mM} \mathrm{NaCl}$, $1 \mathrm{mM} \mathrm{CaCl}_{2}, 1 \mathrm{mM} \mathrm{MgCl}_{2}, 1 \mathrm{mM} \mathrm{MnCl} 2, \mathrm{pH} 7.4$ ) and adsorbed to 96well $(100 \mu \mathrm{L} /$ well) high-binding microtiter plates (Greiner, Lumitrac 600) overnight at $4{ }^{\circ} \mathrm{C}$. Nonspecific receptor-binding sites were blocked with $1 \%$ BSA in buffer $2(200 \mu \mathrm{L} /$ well $)$. Following incubation for $1 \mathrm{~h}$ at room temperature, the plates were washed twice with buffer 3 (buffer 2 containing 0.1\% Tween-20). The potential antagonists were serially diluted with buffer 2 containing $0.1 \%$ of BSA and test solutions added ( $50 \mu \mathrm{L} /$ well) together with biotinylated fibrinogen $(50 \mu \mathrm{L} /$ well, $1: 42$ dilution of stock solution in buffer 2 containing $0.1 \%$ of BSA) to each well. The plates were incubated for $2 \mathrm{~h}$ at room temperature, and then washed twice with buffer 3 . Peroxidase-conjugated antibiotin goat antibody (100 $\mu \mathrm{L} /$ well of a 1:1000 dilution of purchased solution (Calbiochem) in buffer 2 containing $0.1 \%$ of BSA) was added to each well and incubated for another hour. The microtiter plates were washed three times with buffer 3. Finally, chemiluminescent substrate (POD, Roche Diagnostics, Boehringer Mannheim) $(100 \mu \mathrm{L} /$ well $)$ was added and the luminescence measured with a BioTek Synergy H4 multimode research reader three times over $10 \mathrm{~min}$. Positive controls received no inhibitors, while negative controls received no receptor. Tirofiban $\left(\mathrm{IC}_{50 \text { (GPIIb/IIIa) }}=0.37 \pm 0.11 \mathrm{nM}\right.$ ) was used as the internal standard. Assays were performed in duplicate and repeated at least three times on various days. The mean experimental data were fitted to the sigmoid model and $\mathrm{IC}_{50}$ values calculated from the dose-response curve.

\section{Acknowledgments}

This work was supported by the Slovenian Research Agency (Grant P1-0208) and Hungarian-Slovenian bilateral project BI-HU/ 09-10-006. Miloš Ilić thanks Ad Futura Foundation for scholarship. The authors thank Professor Roger Pain for critical reading of the manuscript.

\section{References}

[1] A.D. Lopez, C.D. Mathers, M. Ezzati, D.T. Jamison, C.J.L. Murray, Global and regional burden of disease and risk factors, 2001: systematic analysis of population health data, Lancet 367 (2006) 1747-1757.
[2] J. Ruef, H.A. Katus, New antithrombotic drugs on the horizon, Expert Opin. Investig. Drugs 12 (2003) 781-797.

[3] R. Castelli, F. Porro, D. Savo, E. Cassinerio, New antithrombotic agents, Panminerva. Med. 48 (2006) 247-256

[4] E. Schaden, S.A. Kozek-Langenecker, Direct thrombin inhibitors: pharmacology and application in intensive care medicine, Intensive Care Med. 36 (2010) 1127-1137.

[5] J.I. Weitz, New oral anticoagulants in development, Thromb. Haemost. 103 (2010) 62-70.

[6] J.P. Piccini, R.D. Lopes, K.W. Mahaffey, Oral factor Xa inhibitors for the prevention of stroke in atrial fibrillation, Curr. Opin. Cardiol. 25 (2010) 312-320.

[7] R.A. Shirk, G.P. Vlasuk, Inhibitors of factor VIIa/tissue factor, Arterioscler. Thromb. Vasc. Biol. 27 (2007) 1895-1900.

[8] E.L. Howard, K.C.D. Becker, C.P. Rusconi, R.C. Becker, Factor IXa inhibitors as novel anticoagulants, Arterioscler. Thromb. Vasc. Biol. 27 (2007) 722-727.

[9] M.P. Gulseth, J. Michaud, E.A. Nutescu, Rivaroxaban: an oral direct inhibitor of factor Xa, Am. J. Health Syst. Pharm. 65 (2008) 1520-1529.

[10] M. Miura, N. Seki, T. Koike, T. Ishihara, T. Niimi, F. Hirayama, T. Shigenaga, Y. Sakai-Moritani, T. Kawasaki, S. Sakamoto, M. Okada, M. Ohta, S.I. Tsukamoto, Potent and selective TF/FVIIa inhibitors containing a neutral P1 ligand, Bioorg. Med. Chem. 14 (2006) 7688-7705.

[11] A. Kranjc, D. Kikelj, L. Peterlin-Mašič, Recent advances in the discovery of tissue factor/factor VIIa inhibitors and dual inhibitors of factor VIIa/factor Xa, Curr. Pharm. Des. 11 (2005) 4207-4227.

[12] S. Sander, C.M. White, Ximelagatran - a new oral anticoagulant, Formulary 39 (2004) 398-404.

[13] A.C. Spyropoulos, Brave new world: the current and future use of novel anticoagulants, Thromb. Res. 123 (2008) S29-S35.

[14] G.J. Hankey, J.W. Eikelboom, Dabigatran etexilate a new oral thrombin inhibitor, Circulation 123 (2011) 1436-1450.

[15] E. Perzborn, S. Roehrig, A. Straub, D. Kubitza, W. Mueck, V. Laux, Rivaroxaban: a new oral factor Xa inhibitor, Arterioscler. Thromb. Vasc. Biol. 30(2010)376-381.

[16] A.G.G. Turpie, New oral anticoagulants in atrial fibrillation, Eur. Heart J. 29 (2008) 155-165.

[17] P.L. Gross, J.I. Weitz, New antithrombotic drugs, Clin. Pharmacol. Ther. 86 (2009) 139-146.

[18] C. Patrono, C. Baigent, J. Hirsh, G. Roth, Antiplatelet drugs, Chest 133 (2008) 199S-233S.

[19] N. Mackman, Triggers, targets and treatments for thrombosis, Nature 451 (2008) 914-918.

[20] J.D. Douketis, Combination warfarin-ASA therapy: which patients should receive it, which patients should not, and why? Thromb. Res. 127 (2011) 513-517.

[21] R. Morphy, C. Kay, Z. Rankovic, From magic bullets to designed multiple ligands, Drug Discov. Today 9 (2004) 641-651.

[22] (a) R. Morphy, Z. Rankovic, Fragments, network biology and designing multiple ligands, Drug Discov. Today 12 (2007) 156-160;

(b) R. Morphy, Z. Rankovic, Designing multiple ligands - medicinal chemistry strategies and challenges, Curr. Pharm. Des. 15 (2009) 587-600;

(c) R. Morphy, Z. Rankovic, Designed multiple ligands. An emerging drug discovery paradigm, J. Med. Chem. 48 (2005) 6523-6543.

[23] (a) M. Ilić, D. Kikelj, J. Ilaš, Multitarget antithrombotic drugs, Curr. Top. Med. Chem. 11 (2011) 2834-2848;

(b) U. Trstenjak, D. Kikelj, Multitarget cardiovascular drugs, Curr. Med. Chem. 18 (2011) 2531-2542.

[24] P. Štefanič, M. Anderluh, J. Ilaš, J. Mravljak, M.S. Dolenc, M. Stegnar, D. Kikelj, Toward a novel class of antithrombotic compounds with dual function. Discovery of 1,4-benzoxazin-3(4H)-one derivatives possessing thrombin inhibitory and fibrinogen receptor antagonistic activities, J. Med. Chem. 48 (2005) 3110-3113.

[25] J. Ilaš, Ž. Jakopin, T. Borštnar, M. Stegnar, D. Kikelj, 3,4-dihydro-2H-1,4benzoxazine derivatives combining thrombin inhibitory and glycoprotein IIb/IIIa receptor antagonistic activity as a novel class of antithrombotic compounds with dual function, J. Med. Chem. 51 (2008) 5617-5629.

[26] (a) M. Correia-da-Silva, E. Sousa, B. Duarte, F. Marques, F. Carvalho, L.M. Cunha-Ribeiro, M.M. Pinto, Polysulfated xanthones: multipathway development of a new generation of dual anticoagulant/antiplatelet agents, J. Med. Chem. 54 (2011) 5373-5384;

(b) M. Correia-da-Silva, E. Sousa, B. Duarte, F. Marques, L.M. Cunha-Ribeiro, M.M. Pinto, Dual anticoagulant/antiplatelet persulfated small molecules, Eur. J. Med. Chem. 46 (2011) 2347-2358;

(c) B. Hechler, M. Freund, G. Alame, C. Leguay, S. Gaertner, J.P. Cazenave, M. Petitou, C. Gachet, The antithrombotic activity of EP224283, a neutralizable dual factor Xa inhibitor/glycoprotein IIbIIIa antagonist, exceeds that of the coadministered parent compounds, J. Pharmacol. Exp. Ther. 338 (2011) 412-420.

[27] J. Ilaš, P.Š. Anderluh, M.S. Dolenc, D. Kikelj, Recent advances in the synthesis of $2 \mathrm{H}$-1,4-benzoxazin-3-(4H)-ones and 3,4-dihydro- $2 \mathrm{H}$-1,4-benzoxazines, Tetrahedron 61 (2005) 7325-7348.

[28] L. Peterlin-Mašič, D. Kikelj, Arginine mimetics, Tetrahedron 57 (2001) 7073 7105.

[29] J. Ilaš, F. Hudecz, H. Süli-Vargha, D. Kikelj, Peptides and pseudopeptides incorporating $D$-Phe-Pro-Arg and Arg-Gly-Asp lead sequences as potential antithrombotic agents, J. Pept. Sci. 14 (2008) 946-953.

[30] M. Ilić, D. Kikelj, J. Ilaš, Fluorinated dual antithrombotic compounds based on 1,4-benzoxazine scaffold, Eur. J. Med. Chem. 50 (2012) 255-263. 
[31] M. Ilić, J. Ilaš, S. Liekens, P. Mátyus, D. Kikelj, Synthesis and antiproliferative activity of 2-(([1,2,4]triazolo[4,3-b]-pyridazin-6-yloxy)methyl)-2,4-dimethyl3,4-dihydro-2H-benzo[b][1,4]oxazine derivatives, Arkivoc (2011) 298-311.

[32] R. Kikumoto, Y. Tamao, T. Tezuka, S. Tonomura, H. Hara, K. Ninomiya, A. Hijikata, S. Okamoto, Selective inhibition of thrombin by $(2 R, 4 R)-4$-methyl1-[N2-[(3-methyl-1,2,3,4-tetrahydro-8-quinolinyl)sulfonyl]-l-arginyl]-2piperidinecarboxylic acid, Biochemistry 23 (1984) 85-90.

[33] S. Okamoto, A. Hijikata, R. Kikumoto, S. Tonomura, H. Hara, K. Ninomiya, A. Maruyama, M. Sugano, Y. Tamao, Potent inhibition of thrombin by the newly synthesized arginine derivative No. 805. The importance of stereostructure of its hydrophobic carboxamide portion, Biochem. Biophys. Res. Commun. 101 (1981) 440-446.

[34] M.S. Egbertson, C.T. Chang, M.E. Duggan, R.J. Gould, W. Halczenko, G.D. Hartman, W.L. Laswell, J.J. Lynch Jr., R.J. Lynch, P.D. Manno, A.M. Naylor, J.D. Prugh, D.R. Ramjit, G.R. Sitko, R.S. Smith, L.M. Turchi, G. Zhang, Nonpeptide fibrinogen receptor antagonists. 2. Optimization of a tyrosine template as a mimic for Arg-Gly-Asp, J. Med. Chem. 37 (1994) 2537-2551.

[35] S.R. Nagarajan, B. Devadas, J.W. Malecha, H.F. Lu, P.G. Ruminski, J.G. Rico, T.E. Rogers, L.D. Marrufo, J.T. Collins, H.P. Kleine, M.K. Lantz, J. Zhu, N.F. Green, M.A. Russell, B.H. Landis, L.M. Miller, D.M. Meyer, T.D. Duffin, V.W. Engleman, M.B. Finn, S.K. Freeman, D.W. Griggs, M.L. Williams, M.A. Nickols, J.A. Pegg, K.E. Shannon, C. Steininger, M.M. Westlin, G.A. Nickols, J.L. Keene, $R$-isomers of Arg-Gly-Asp (RGD) mimics as potent $\alpha_{\mathrm{V}} \beta_{3}$ inhibitors, Bioorg. Med. Chem. 15 (2007) 3783-3800.

[36] We have recently described the preparation of racemic 1,4-benzodioxine compounds in M. Ilić, J. Ilaš, P. Dunkel, P. Mátyus, A. Boháč, S. Liekens, D. Kikelj, Novel 1,4-benzoxazine and 1,4-benzodioxine inhibitors of angiogenesis, Eur. J. Med. Chem. 58 (2012) 160-170.

[37] A. Wykretowicz, P. Guzik, K. Wysocki, Doxazosin in the current treatment of hypertension, Expert Opin. Pharmacol. 9 (2008) 625-633.

[38] A. Pietrangelo, F. Borella, G. Casalgrandi, G. Montosi, D. Ceccarelli, D. Gallesi, F. Giovannini, A. Gasparetto, A. Masini, Antioxidant activity of silybin in vivo during long-term iron overload in rats, Gastroenterology 109 (1995) 19411949.

[39] K. Rácz, J. Fehér, G. Csomós, I. Varga, R. Kiss, E. Glaz, An antioxidant drug, silibinin, modulates steroid secretion in human pathological adrenocortical cells, J. Endocrinol. 124 (1990) 341-345.

[40] L. Cavallini, A. Bindoli, N. Siliprandi, Comparative evaluation of antiperoxidative action of silymarin and other flavonoids, Pharmacol. Res. Commun. 10 (1978) 133

[41] I. Altorjay, L. Dalmi, B. Sári, S. Imre, G. Balla, The effect of silibinin (Legalon) on the free radical scavenger mechanisms of human erythrocytes in vitro, Acta Physiol. Hung 80 (1992) 375-380.
[42] I. György, S. Antus, A. Blázovics, G. Földiák, Substituent effects in the free radical reactions of silybin: radiation-induced oxidation of the flavonoid at neutral pH, Int. J. Radiat. Biol. 61 (1992) 603-609.

[43] D.K. Sharma, I.H. Hall, Hypolipidemic, antiinflammatory, and antineoplastic activity and cytotoxicity of flavonolignans isolated from Hydnocarpuswightiana seeds, J. Nat. Prod. 54 (1991) 1298-1302.

[44] M.T. Vázquez, G. Rosell, M.D. Pujol, Synthesis and antiinflammatory activity of 2,3-dihydro-1,4-benzodioxin methyl carboxylic acids, Farmaco 51 (1996) 215-217.

[45] Y. Harrak, G. Rosell, G. Daidone, S. Plescia, D. Schillaci, M.D. Pujol, Synthesis and biological activity of new anti-inflammatory compounds containing the 1,4-benzodioxine and/or pyrrole system, Bioorg. Med. Chem. 15 (2007) 48764890.

[46] H. Itazaki, A. Kawasaki, M. Matsuura, M. Ueda, Y. Yonetani, M. Nakamura Synthesis of 2,3-dihydro-1,4-benzodioxin derivatives. I. 2-substituted 5 (and 6)-sulfamoyl-2,3-dihydro-1,4-benzodioxins, Chem. Pharm. Bull. 36 (1988) 3387-3403.

[47] M.G. Kelly, J. Kincaid, M. Duncton, K. Sahasrabudhe, S. Janagani, R.B. Upasani, G. Wu, Y.F. Fang, Z.L. Wei, C. Kaub, J. He, Amide derivatives as ion-channe ligands and pharmaceutical compositions and methods of using the same 2006. US 2008/0300243 A1.

[48] N.H. Hauel, H. Nar, H. Priepke, U. Ries, J.M. Stassen, W. Wienen, Structurebased design of novel potent nonpeptide thrombin inhibitors, J. Med. Chem. 45 (2002) 1757-1766.

[49] T. Xiao, J. Takagi, B.S. Coller, J.H. Wang, T.A. Springer, Structural basis for allostery in integrins and binding to fibrinogen-mimetic therapeutics, Nature 432 (2004) 59-67.

[50] M. Comini, C. Pozzoli, M. Incerti, D. Rossi, S. Collina, O. Azzolina, Di E. Vittorio G. Morini, E. Poli, Stereospecific effects of benzo[d]isothiazolyloxypropanolamine derivatives at $\beta$-adrenoceptors: synthesis, chiral resolution, and biological activity in vitro, Chirality 21 (2009) 284-291.

[51] J.M. Klunder, S.Y. Ko, K.B. Sharpless, Asymmetric epoxidation of allyl alcohol: efficient routes to homochiral $\beta$-adrenergic blocking agents, J. Org. Chem. 51 (1986) 3710-3712.

[52] N. Buizer, C.G. Kruse, M. Van der Laan, G. Langrand, G.J.M. Van Scharrenburg, M.C. Snoek, Enzymatic Process for the Stereoselective Preparation of a Heterobicyclic Alcohol Enantiomer (1994). EP0605033 (A1).

[53] G.M. Morris, R. Huey, W. Lindstrom, M.F. Sanner, R.K. Belew, D.S. Goodsell, A.J. Olson, Autodock4 and AutoDockTools4: automated docking with selective receptor flexibility, J. Comput. Chem. 16 (2009) 2785-2791.

[54] Y. Cheng, W.H. Prusoff, Relationship between the inhibition constant $\left(K_{\mathrm{i}}\right)$ and the concentration of inhibitor which causes $50 \%$ inhibition $\left(\mathrm{IC}_{50}\right)$ of an enzymatic reaction, Biochem. Pharmacol. 22 (1973) 3099-3108. 